\title{
6 Designbasierte Studie
}

\section{Die gestalteten Elaborationsvarianten im Test}

Nach der Auslegeordnung des Gesamtmaterials, den zwölf Expertenanalysen und der Erarbeitung von Elaborationstypen, Imperfektionen und Wirkungsweisen aus dem Untersuchungskorpus werden im letzten Kapitel der praxisbasierten Studie die gewonnenen Erkenntnisse mit der Methode des «Research through Design> hypothesenartig auf Gestaltungsvarianten unterschiedlicher Elaborationsgrade angewendet und an einem gestalterischen Laienpublikum (20 Probanden) getestet. Die Elaborationsvarianten, die eigens für diesen Zweck gestaltet wurden, basieren auf drei Originalbeispielen aus dem Untersuchungskorpus, die in der rhetorischen Detailanalyse genauer betrachtet wurden und aufgrund der Experteneinschätzungen eine spannende und aussagekräftige Konstellation für das Untersuchungsdesign versprachen. Es sind dies der Wahlprospekt der BDP Schüpfen, das Flugblatt der Freiwilligen Feuerwehr Zollikofen und das Veranstaltungsplakat des 〈Moditreff〉 Bern. Ein Beispiel stammt somit aus dem Kontext der lokalpolitischen Kommunikation, die zwei anderen Ausgangsexemplare aus unterschiedlichen Bereichen der Gemeinwesenarbeit.

\subsection{Die Varianten im Überblick: Elaborationsmerkmale und Wirkungshypothesen}

Die experimentell gestalteten Varianten wurden so konzipiert, dass sie durch kleinere bis mittlere elaborative Abweichungen vom gewählten Ausgangsartefakt eine jeweils stärker oder weniger stark ausgearbeitete Variation des bestehenden Kommunikationsmittels bilden, um durch die relative Nähe zu den benachbarten Varianten die Überprüfung von Wirkungshypothesen zu ermöglichen. Hierzu setzt jede Variante vorgängig festgelegte Elaborationsmerkmale um, die mit je spezifischen Wirkungsannahmen verbunden sind und mit einem der Elaborationstypen korrespondieren, wie sie in der rhetorischen Designanalyse vorgefunden wurden. Zuerst werden im Folgenden die neun Elaborationsvarianten präsentiert: Welchen Elaborationsgrad und -typ weisen sie auf? Welche Elaborationsmerkmale sind in der Variante umgesetzt und welche damit verbundenen Wirkungsannahmen oder Fragen ergeben sich daraus für die Wirkungsstudie? 


\subsubsection{Designvarianten Wahlprospekt BDP}

Als Grundlage für die Gestaltung der Designvarianten des Wahlprospekts der BDP für die Gemeindewahlen in Schüpfen dient der konventionell gestaltete, in der Expertenanalyse als «durchschnittlich» eingestufter Originalprospekt aus dem Untersuchungskorpus (BDP S 392). Dieses Original bildet in der ersten Versuchsreihe die mittlere Variante, von der ausgehend eine weniger elaborierte Variante kreiert wurde, die einen semiprofessionellen Anstrich hat, und eine elaboriertere Variante, die als sehr professionell hervorstechen sollte (für eine Übersicht der Varianten, Elaborationsmerkmale und Wirkungshypothesen siehe Tabelle und Grafik 25).

Aufgrund der Neugestaltung von zwei Designvarianten eines bestehenden Wahlprospekts und der anschließenden Befragung sollte herausgefunden werden, wie unterschiedliche Elaborationsgrade in der Wahlkommunikation sich beim potenziellen Publikum auswirken. Bewährt sich die klassische Form des Wahlprospekts? Wäre im gegebenen lokalpolitischen Kontext eine höhere gestalterische Qualität wünschenswert? Oder wird gar die am wenigsten professionelle Gestaltungsform als die angemessenste erachtet? Welche Rolle spielen bewusst 〈handgemachte〉 oder auf mangelndes gestalterisches Können zurückzuführende Gestaltungselemente? Und wie wirkt sich der jeweilige Elaborationsgrad auf die Wahrnehmung der Absenderpartei aus?

Die niedrige Variante sollte den klassischen Aufbau des Originals verwenden, jedoch in Bezug auf Layout, Typografie und Ausführung weniger professionell umgesetzt sein, so dass sich ein etwas hemdsärmeliger und undefinierter Gesamteindruck ergibt. Der Prospekt sollte nicht laienhaft erscheinen, sondern in der Manier daherkommen, wie ihn eine kleinere Druckerei auf dem Land gestalten würde. Hierfür wurde das Titelbild mit den Kandidierenden nicht ganz sauber freigestellt und auf einen rasterartigen Hintergrund gesetzt, der nur ungefähr die gelbe Corporate-Farbe der Partei aufnimmt. Vorne und hinten sind zwei kleinformatige, nicht professionell fotografierte Bilder hinzugefügt, deren Zweck nicht ganz klar ersichtlich ist und die das Gesamtbild stören. Schriftgestaltung und Layout sind holprig und enthalten kleine Unsauberkeiten. Die Fotos auf den Innenseiten sind in verminderter Qualität abgebildet. Durch das verwendete Glanzpapier in niedriger Grammatur («Magno Star` $90 \mathrm{~g} / \mathrm{m}^{2}$, glänzend, dreifach gestrichen, hochweiß) sollte der Prospekt optisch und haptisch billig wirken. Aufgrund der Expertenanalyse wäre zu vermuten, dass dieser Prospekt zwar aufgrund seiner handgestrickten Gestaltungsweise Sympathien weckt, jedoch selbst für den Bereich der ländlichen, lokalen politischen Kommunikation zu wenig elaboriert ist - besonders auch, weil hier eine bürgerliche und relativ bekannte Partei wirbt. 


\section{Designvarianten Wahlprospekt BDP}

\begin{tabular}{|c|c|c|}
\hline $\begin{array}{l}\text { Elaborationsgrad \& } \\
\text { Elaborationstyp }\end{array}$ & Elaborationsmerkmale & Erwartete Wirkung \\
\hline $\begin{array}{l}\text { niedrig } \\
\text { undefiniert }\end{array}$ & $\begin{array}{l}\text { - semi-professionell/Polygrafenarbeit } \\
\text { - holpriges Layout, grobe Typografie } \\
\text { - Abweichungen vom Corporate Design } \\
\text { - ohne gestalterisches Konzept } \\
\text { - nach Muster des klassischen Wahlprospekts } \\
\text { - überflüssige Elemente, wenig Weißraum } \\
\text { - niedrige Bildqualität, Mängel bei der Bildbe- } \\
\text { arbeitung } \\
\text { - Farblaserdruck } \\
\text { - billige Papierqualität: niedrige Grammatur } \\
90 \mathrm{~g} / \mathrm{m}^{2}, \text { glänzend, dreifach gestrichen }\end{array}$ & $\begin{array}{l}\text { - handgestrickt } \\
\text { - billig } \\
\text { - gesichtslos } \\
\text { - überladen } \\
\text { - unseriös } \\
\text { - zu wenig elabo- } \\
\quad \text { riert? }\end{array}$ \\
\hline $\begin{array}{l}\text { mittel } \\
\text { konventionell }\end{array}$ & - Originaler Wahlprospekt BDP Schüpfen & \\
\hline hoch & $\begin{array}{l}\text { - professionell } \\
\text { - durchdachtes Layout, saubere Typografie }\end{array}$ & $\begin{array}{l}\text { - hochwertig } \\
\text { - ansprechend }\end{array}$ \\
\hline herausragend & $\begin{array}{l}\text { - einheitliche Sprache, klare Linie } \\
\text { - gestalterisches Konzept, das nicht allzu } \\
\text { originell sein will } \\
\text { - in Format und Faltung vom klassischen Wahl- } \\
\text { prospekt abweichend } \\
\text { - auf das Nötige reduziert, viel Weißraum } \\
\text { - sehr gute Bildqualität } \\
\text { - Offset-Druckqualität } \\
\text { - hochwertige Papierqualität: hohe Grammatur } \\
120 \mathrm{~g} / \mathrm{m}^{2} \text {, matt, superweiß }\end{array}$ & $\begin{array}{l}\text { - zuverlässig } \\
\text { - zu elaboriert? }\end{array}$ \\
\hline
\end{tabular}




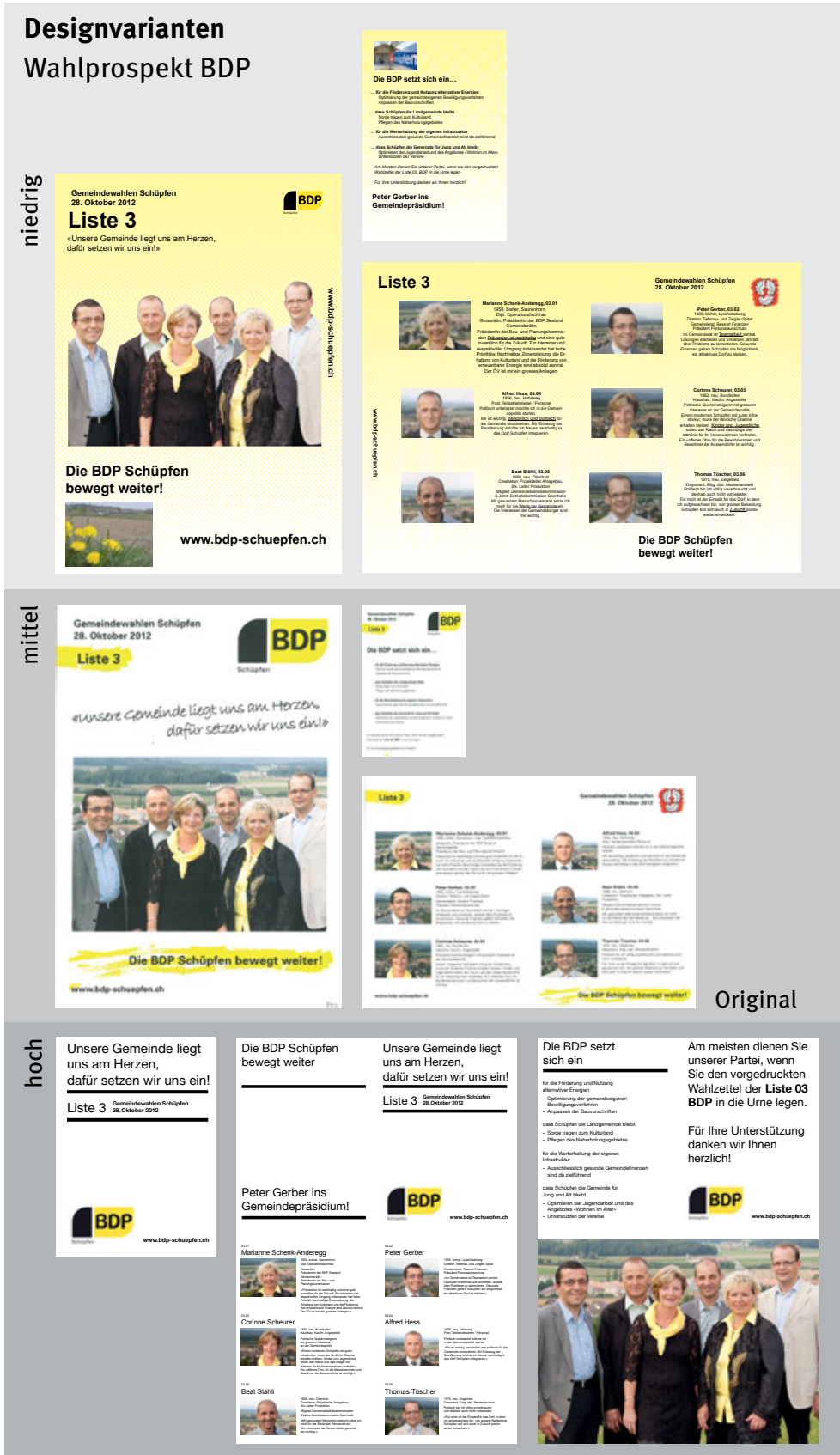

Grafik 25: Übersicht Designvarianten Wahlprospekt BDP Schüpfen 
Der als mittlere Variante verwendete Original-Wahlprospekt der BDP Schüpfen wird in der Expertenanalyse als biederes und wenig inspiriertes Beispiel angesehen, das in für Wahlkommunikation typischer Aufmachung daherkommt: Ein Gruppenbild und ein Slogan auf der Vorderseite, innen die Porträts der Kandierenden mit Begleittext. Der Prospekt enthält keine gröberen gestalterischen Fehler und wirkt aus Sicht der Experten insgesamt knapp professionell. Kritisch beurteilt werden in der Expertenanalyse die auf selbstgemacht getrimmten Stilmittel: Die gelben Pinselstrichmarkierungen und der Text in Pseudohandschrift erscheinen aus Expertensicht unbeholfen, anbiedernd und in kontraintentionaler Weise nicht kreativ. Würde das Laienpublikum diese Einschätzungen bestätigen?

Die hoch elaborierte Variante des Wahlprospekts sollte sich mit einer vom Standardprospekt abweichenden, durchgehend professionellen und hochwertigen Erscheinung aus der Masse hervorheben, ohne besonders originell sein $\mathrm{zu}$ wollen. Hierfür wurde ein großes Format (A3) in zweifacher Faltung gewählt, das zunächst in der gewohnten Form (A5 hoch) jedoch ohne Bild in Erscheinung tritt, und erst durch zweifaches Auffalten und Umdrehen allmählich Inhalte und Fotos enthüllt - und seine 〈wahre Größe〉 entfaltet. Das generöse Format ermöglichte die Platzierung einer auffälligen, großformatigen Abbildung des Gruppenfotos und den ausgeprägten Einsatz von Weißraum. Sowohl die Vorder- als auch die Rückseite funktionieren, wenn sie ganz aufgefaltet werden, als Plakat. Alle Fotos sind in hoher Qualität abgebildet. Das Layout ist schlicht und auf das Wesentliche reduziert, die Schrift durchgehend in der bodenständigen, aber doch subtilen Schrift 〈Helvetica〉 gehalten. Als stilprägendes und strukturierendes Stilmittel wurde eine dicke schwarze Linie eingesetzt. Das verwendete Papier ist hochwertig und matt («Eminent〉 FSC $120 \mathrm{~g} / \mathrm{m}^{2}$, superweiß, holzfrei) und soll für eine gute, angenehme Optik und Haptik sorgen. Der Druck erfolgte in bester Offset-Qualität (wegen der zu kleinen Auflage wurde dies mittels 〈Indigo〉-Druck simuliert). Aufgrund der genannten Elaborationsmerkmale wäre zu erwarten, dass der Prospekt auf die Testpersonen professionell und hochwertig sowie ästhetisch ansprechend wirkt und einen seriösen Eindruck hinterlässt. Unter Berücksichtigung des Kontexts lokaler Wahlen auf dem Land und des konservativen Absenders könnte der Elaborationsgrad hier aber unter Umständen bereits zu hoch sein.

\subsubsection{Designvarianten Aushang Mädchentreff}

Beim Veranstaltungsprogramm des Statdberner «Moditreff〉 dient der Originalaushang als Ausgangspunkt für zwei elaboriertere Varianten (für eine Übersicht aller Varianten, ihrer Elaborationsmerkmale und Wirkungshypothesen siehe Tabelle und Grafik 26). Mit der Gestaltung und Prüfung von Varianten, welche 
unterschiedliche laienhafte, imperfekte und selbstgemachte Aspekte des Originals aufnehmen, diese jedoch sauberer ausarbeiten, sollte nochmals der Frage nachgegangen werden, wie Aspekte des Selbstgemachten, Laienhaften und Imperfekten auf unterschiedliche Betrachterinnen und Betrachter einwirken und welcher gestalterische Elaborations- bzw. Perfektionierungsrad diesen im gegebenen Kontext angemessen erscheint. Lässt sich das Laienhafte überzeugend und authentisch inszenieren oder gehen diese Aspekte durch die Elaboration unweigerlich verloren? Kann das Produkt noch problemlos in den Rahmen der Quartierarbeit eingeordnet werden, wenn es sich vom typischen Genre der Wordgestaltung entfernt? Und wie beeinflussen die Imperfektionen oder Perfektionierungsversuche das Laienpublikum?

Wie in der Detailanalyse formuliert, ist die originale Variante «niedrig ein aus Expertensicht offensichtlich unprofessionell gestaltetes Produkt, das selbst für den Bereich Gemeinwesenarbeit, der stark von Laiengestaltung geprägt ist, auffallend wenig ausgearbeitet erscheint. Gleichzeitig stechen die von Hand hinzugefügten und kolorierten Elemente und die wilde Schriftgestaltung ins Auge. Unter den Gestaltungsexperten war man sich nicht einig, ob die selbstgebastelte und dilettantische Erscheinung auf eine schludrige und lieblose Machart hindeutet oder ob der Aushang dadurch gerade charmant, unbeschwert und verspielt wirkt und ein gewisses Engagement zum Ausdruck kommt. Würde dies vom Laienpublikum ebenso kontrovers beurteilt oder findet sich hier ein Konsens?

Für die Gestaltung der mittleren Variante sollten jene Elemente des Originals, die aufgrund ihrer selbstgemachten Erscheinung engagiert wirken und etwas Verspieltes verbreiten, aufgenommen und in sauberer und leicht professionellerer Weise umgesetzt werden. Die Produktionsqualität sollte ebenfalls geringfügig verbessert, das A4-Standardformat und Recyclingpapier jedoch beibehalten werden. Die Gestaltungsvariante «mittel» setzt mit leuchtenden, klebezettelartigen Quadraten auf die bunte Farbigkeit und auf die etwas verquere Schreibmaschinenästhetik, wie wir sie vom Original her kennen. Sie tut dies jedoch in klarer und aufgeräumter Weise, um das Angebot des Treffs möglichst rasch und verständlich zu kommunizieren. Das selbstgebastelte Logo des Treffs wurde als Header eins zu eins übernommen. In der Mitte wurde mit den kreuz und quer übereinander gelagerten grauen Balken, auf denen in einer freundlichen und verspielten Schrift («Minion Pro») das gesamte Angebot des Treffs zu sehen bzw. zu erraten ist, die Charakteristik des Titelschriftzugs aufgenommen sowie das kreative Chaos und die unbeschwerte Art zum Ausdruck gebracht, wie sie die niedrige Variante verströmt. Gedruckt ist die mittlere Variante in wenig aufwändiger Produktionsweise mit einem Farb-Laserdrucker auf A4-Recyclingpapier («Pro Futura〉 FSC «Blauer Engel〉, $115 \mathrm{~g} / \mathrm{m}^{2}$, matt, ISO Weiße 80, 100\% Altpapier, $\mathrm{CO}_{2}$-neutral). Wenn das Experiment gelingt, wäre eine unbeschwerte, mädchenhafte und charmante 


\section{Designvarianten Aushang Mädchentreff}

\begin{tabular}{|c|c|c|}
\hline $\begin{array}{l}\text { Elaborationsgrad \& } \\
\text { Elaborationstyp }\end{array}$ & Elaborationsmerkmale & Erwartete Wirkung \\
\hline $\begin{array}{l}\text { niedrig } \\
\text { unkompliziert }\end{array}$ & - originaler Aushang «Moditreff` Bern & \\
\hline \multirow[t]{2}{*}{ mittel } & - semiprofessionell bis professionell & - frisch \\
\hline & - Gestaltungsidee, die mit vorhandenen Ele- & - persönlich \\
\hline \multirow[t]{4}{*}{ engagiert } & $\begin{array}{l}\text { menten arbeitet: Laiengrafik, handgemachter } \\
\text { Touch, chaotisches Layout }\end{array}$ & $\begin{array}{l}\text { - charmant } \\
\text { - unbeschwert }\end{array}$ \\
\hline & $\begin{array}{l}\text { - aufwändiger in Produktion, aber immer noch } \\
\text { low-tech }\end{array}$ & $\begin{array}{l}\text { - mädchenhaft } \\
\text { - Idee gelungen? }\end{array}$ \\
\hline & - Farb-Laserdruck & \\
\hline & $\begin{array}{l}\text { - Recyclingpapier A4 beibehalten, aber in } \\
\text { besserer Qualität } 115 \mathrm{~g} / \mathrm{m}^{2} \text {, matt }\end{array}$ & \\
\hline
\end{tabular}

\begin{tabular}{lll}
\hline hoch & - professionell & - sachlich \\
konventionell & - aufgeräumtes Layout, viel Weißraum & - informativ \\
& - klassische Veranstaltungsinformation & - zuverlässig \\
& - den amtlichen Auftrag betonen, einen Hauch & - zu elaboriert? \\
& Mädchenhaftigkeit bewahren & \\
& - einfache Produktion beibehalten & \\
& - Farb-Laserdruck \\
& - hochwertiges Recyclingpapier A4 \\
& $115 \mathrm{~g} / \mathrm{m}^{2}$, matt & \\
& \\
& \\
\end{tabular}




\section{Designvarianten}

\section{Aushang Mädchentreff}

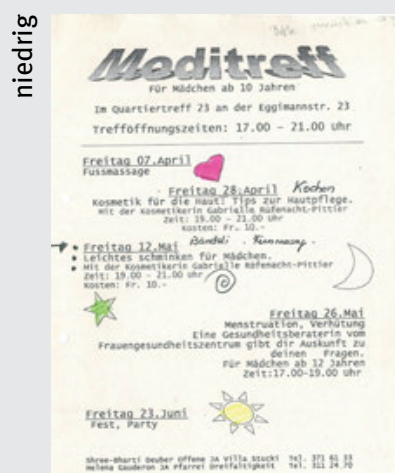

Original

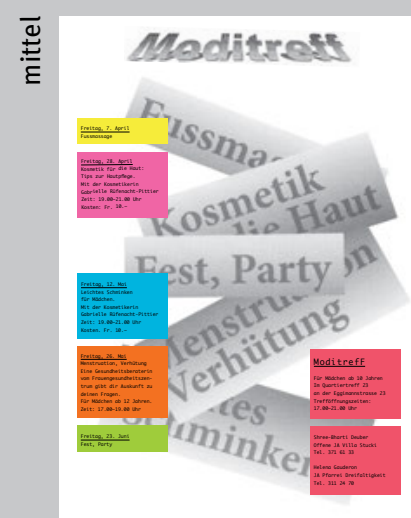

\section{등 moditreff frühling}

Fussmassage

*

Kosmetik

für die Hau

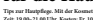

(2)

Leichtes Schminken

für Mädchen

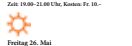

Menstruation,

Verhütung

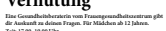

Fest, Party

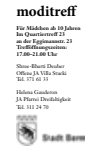

Grafik 26: Übersicht Designvarianten «Moditreff` Bern 
Wirkung zu erwarten. Es könnte aber auch sein, dass die Übertragung der selbstgemachten, dilettantischen Elemente in eine professionelle Form für Irritation sorgt.

Die Variante «hoch räumt mit dem Gewirr definitiv auf. Sie sollte professionell wirken und den amtlichen Auftrag kenntlich machen. Für die Gestaltung wurde durchgehend die verspielt-freundliche und doch saubere Schrift «Minion Pros in einer klaren und hierarchisch strukturierten Anordnung verwendet. Der Absenderblock mit dem Logo der Stadt Bern betont den offiziellen Charakter. Die bunten Symbole, die sich an die Leuchtstiftmotive des Originals anlehnen, sollen etwas Verspieltes und Mädchenhaftes in die Gestaltung hineinbringen. Durch die Verwendung von mattem Recyclingpapier (ebenfalls «Pro Futura FSC «Blauer Engel〉, $115 \mathrm{~g} / \mathrm{m}^{2}$ ) und den einfachen Laserdruck wird die Produktionsweise auch bei der hohen Variante immer noch bewusst günstig und unkompliziert gehalten. Durch die professionelle und sachliche Umsetzung wird erwartet, dass das Plakat einen sauberen und zuverlässigen Eindruck hinterlässt, dank der bunten und verspielten Details aber immer noch einen Bezug zu den Mädchen schafft. Allerdings könnte der Aushang im gegebenen Kontext bereits zu elaboriert sein.

\subsubsection{Designvarianten Flugblatt Freiwillige Feuerwehr}

Der Originalflyer der Freiwilligen Feuerwehr Zollikofen bildet in dieser Dreiergruppe die Variante mit dem niedrigsten Elaborationsgrad, von der ausgehend zwei Varianten gestaltet wurden, die unterschiedlich stark vom Original abweichen und jeweils einen etwas höheren Elaborationsgrad aufweisen (vgl. Tabelle und Grafik 27 für eine Übersicht aller Varianten, ihrer Elaborationsmerkmale und Wirkungshypothesen). Auch hier sollte die Versuchsanordnung mit den drei unterschiedlich elaborierten Varianten die Frage beantworten, wie elaboriert, wie originell, wie herausragend Gestaltung im Kontext der Gemeinwesenarbeit sein soll und darf. Ist es am erfolgversprechendsten, die bestehenden Sehgewohnheiten $\mathrm{zu}$ bedienen und möglichst in üblicher Manier zu gestalten? Reichen ein mittlerer Elaborationsgrad, mittelmäßige Profigestaltung oder gar semiprofessionelle, gestalterisch fehlerhafte Arbeit vollkommen aus? Besteht vielleicht auch in diesem Bereich ein Bedürfnis nach Originalität und gestalterischer Exzellenz - oder wirken hochprofessionelle Elaborationsformen im gegebenen Kontext übertrieben und falsch?

Wie in der Detailanalyse ausführlich geschildert, wird das originale Flugblatt bzw. die niedrige Variante von den Experten als aus gestalterischer Sicht banales, aber durchaus zweckmäßiges Kommunikationsmittel beurteilt. Es zeigt den Interessierten amateurfotografierte Szenen aus dem Feuerwehralltag und ruft sie zur Teilnahme auf. Die Vorderseite legt den Schwerpunkt auf die emotionale Anspra- 
che des Zielpublikums, auf der Rückseite sind weiterführende Informationen zu finden. Bei den Imperfektionen, die von den Experten als Amateurfehler eingeordnet wurden, fällt einerseits die verwendete Technik des hinterlegten Bilds auf, die in der Profigestaltung verpönt ist. Andererseits sticht das unverhältnismäßig große Logo des Absenders ins Auge, das technisch nur grob ausgearbeitet ist. Als unüblich für visuelle Kommunikationsmittel im Bereich der Freiwilligenarbeit fiel der Einsatz einer (wenig originellen) visuell-verbalen Figur («Mit der Feuerwehr hoch hinaus! () auf. Die Experten waren sich am Ende uneinig darüber, ob mit der niedrigen Variante ganz einfach ein austauschbares und fades gestalterisches Produkt vorliegt oder ob das Flugblatt in seiner Normalität und Nüchternheit seriös und angemessen ist und in seiner Unbedarftheit und Fehlerhaftigkeit gerade sympathisch und authentisch wirkt. Wie würde das Laienpublikum dies wohl beurteilen?

Für die Gestaltung der mittleren Variante sollte durch einen solideren Umgang mit Schrift und Bild ein leicht professionelleres Erscheinungsbild erlangt werden, die vorhandene Charakteristik des Originals sollte jedoch nur sanft verändert und der konventionelle Aufbau und die genretypische Gestaltungsweise beibehalten werden. Hierfür wurde anstatt der vielen kleinen Amateurfotos ein professionelleres, aussagekräftiges Foto großformatig und randabfallend in Szene gesetzt und auf das Hintergrundbild vorne und hinten wurde verzichtet. Die Kernsätze sind klarer hervorgehoben und der Text - wie beim Original in «Arial〉 gesetzt - ist sauberer strukturiert. Auf der Rückseite wurde aufgrund der gewählten Zeichenzahl pro Zeile ein linksbündiger Flattersatz gewählt, was gepflegter und besser lesbar ist als der Blocksatz des Originalflyers. Das Logo ist kleiner platziert, behält aber seine unprofessionelle Form. Für die Produktion wurden ein leicht schwereres, mattes, Papier (〈Superset〉 FSC, $120 \mathrm{~g} / \mathrm{m}^{2}$, superweiß, holzfrei) und ein Farb-Laserdrucker verwendet. Die beschriebenen Elaborationsmerkmale, die sich nahe am Original bewegen, dürften das Produkt immer noch konventionell und dadurch verständlich wirken lassen. Durch den simplen Ansatz und eine leichte Unbeholfenheit in der Ausführung wäre zu erwarten, dass der Flyer nahe bei den Leuten bleibt und sympathisch wirkt. Gleichzeitig könnte die sauberere und konsequentere Umsetzung einen professionelleren und damit leicht seriöseren Eindruck hinterlassen. Die entscheidende Frage wird sein, ob die Steigerung des Elaborationsgrads bei den Befragten als Verbesserung angesehen wird oder bereits für Befremden sorgt.

Bei der Variante «hoch > bildet ein originelles Gestaltungskonzept die Grundlage für die Gestaltung. Das Produkt sollte auf allen Ebenen professionell wirken. In der elaborierten Variante kombiniert der Feuerwehrflyer einen markanten Schriftzug mit Bändern in unterschiedlichen Orangetönen und Schwarz. Die Gestaltung nimmt optisch Bezug auf die Streifen in Warnfarben, die auf 


\section{Designvarianten Flugblatt Freiwillige Feuerwehr}

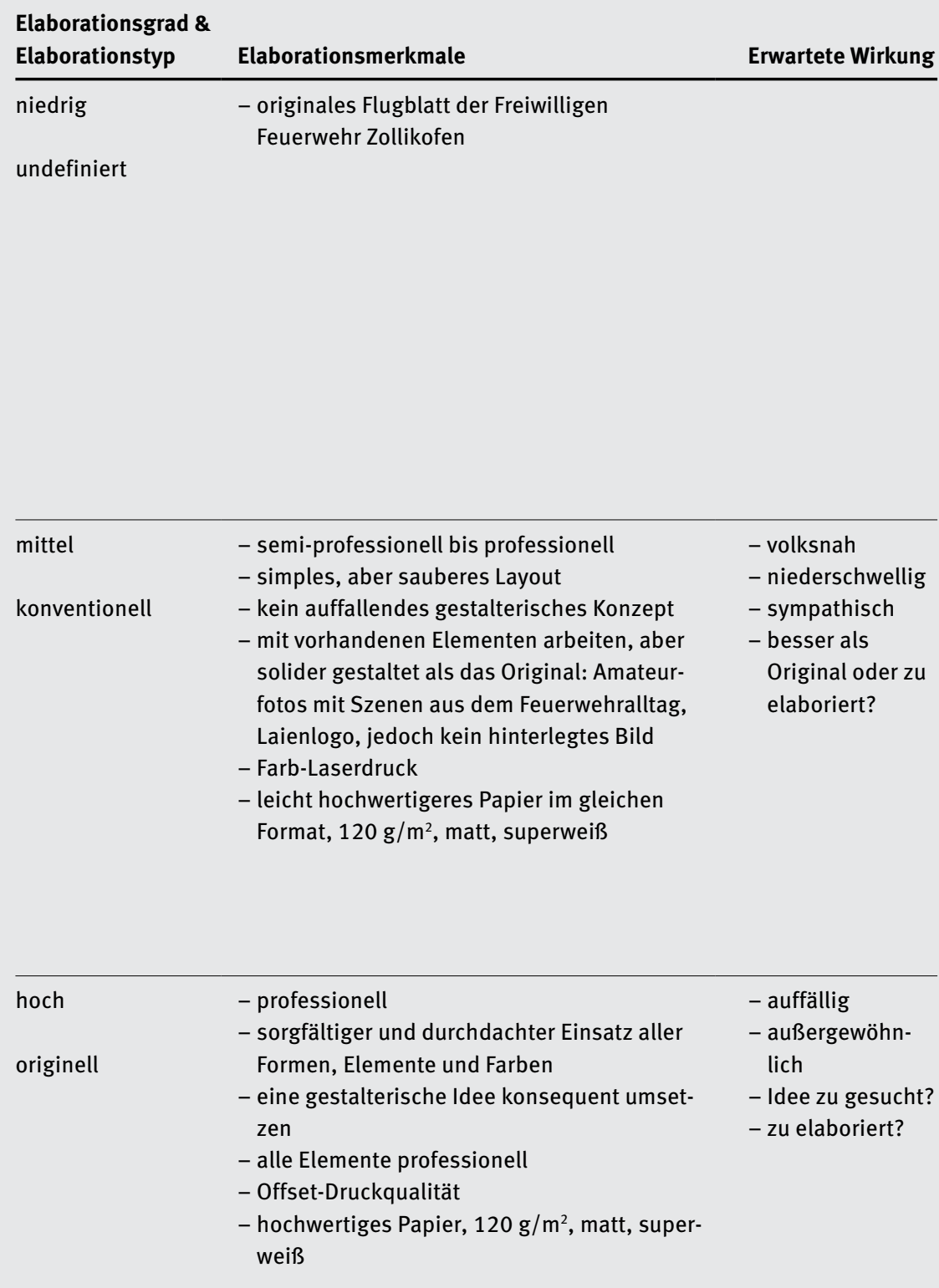




\section{Designvarianten}

Flugblatt Freiwillige Feuerwehr


Original
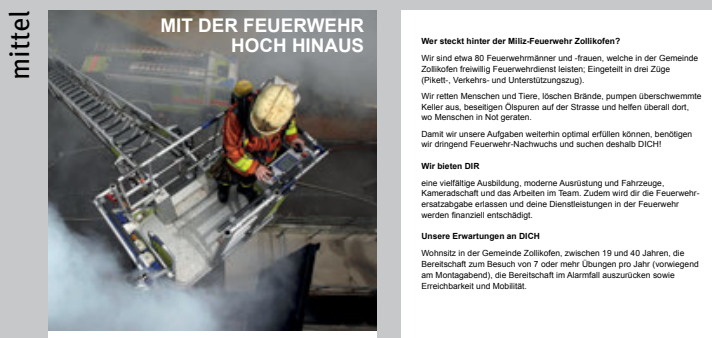

Wir suchen DICH für den aktiven Feuerwehrdienst!

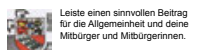

Mach mit bei unst

\section{高 \\ Wir suchen dich \\ für den aktiven \\ Feuerwehrdienst!}

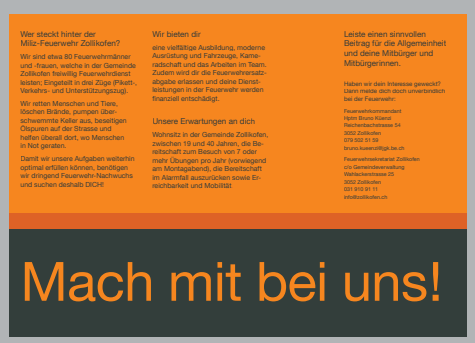

Grafik 27: Übersicht Designvarianten Freiwillige Feuerwehr Zollikofen 
Kleidung und Einsatzwagen der Feuerwehr zu sehen sind. Dadurch sollte in origineller Weise, jedoch ohne es dem Betrachter aufs Auge zu drücken, ein Bezug zur Feuerwehr geschaffen und zugleich eine augenfällige und plakative, aber auch anregende und frische Wirkung erlangt werden. Mit der «Helvetica» wurde eine einfache, klare, alltägliche und mit der in den anderen Varianten verwendeten 〈Arial〉 vergleichbare Schrift verwendet, die aber ausgewogener und moderner wirkt. Zugunsten einer konsequenten Umsetzung der Gestaltungsidee und zur Erreichung der optimalen Wirksamkeit der eingesetzten typografischen, formalen und farblichen Stilmittel wurde auf fotografische Hilfsmittel sowie das Logo komplett verzichtet. Neben der rein typografischen Umsetzung besteht ein weiterer Unterschied zu den beiden anderen Varianten im gewählten Querformat, das die Idee der Bänder sowie die Lesbarkeit des groß geschriebenen Aufrufs auf der Frontseite unterstützen sollte. Bei der Produktion der Variante 〈hoch〉 wurde wie schon bei der mittleren Variante leicht dickeres, mattes, holzfreies Papier («Eminent〉 FSC, $120 \mathrm{~g} / \mathrm{m}^{2}$ ) verwendet und sie ist nochmals aufwändiger in Offset-Druckqualität gedruckt (mittels «Indigo〉-Druck, da die Auflage für Offset zu klein war). Trotz der deutlichen Abweichungen wurde darauf geachtet, dass sich die Variante immer noch ausreichend an das Original und die mittlere Variante anlehnt, um mit diesen vergleichbar zu bleiben. Der Text und die einfache, doppelseitige Aufteilung der Informationen auf das Format A5 wurden ungefähr beibehalten. Aufgrund der beschriebenen Elaborationsmerkmale wäre zu erwarten, dass die Variante 〈hoch〉 auf die Versuchspersonen hochwertig und professionell sowie auffällig, außergewöhnlich und originell wirkt. Es könnte jedoch sein, dass diese Variante $\mathrm{zu}$ elaboriert ist und ihr Publikum aufgrund ihrer untypischen Form irritiert.

\subsection{Resultate Designvarianten Wahlprospekt BDP}

In der Wirkungsstudie, die als Basis für die nun folgende Auswertung dient, wurden zwanzig Personen zu allen neun Elaborationsvarianten - also zu den Originalen und den neu gestalteten Varianten - befragt. Die Testpersonen wurden bei der Befragung nicht eingeweiht, ob es sich bei einer Variante um ein Original oder eine abgeleitete, experimentelle Variante handelte. Außerdem wurden ihnen die Varianten in wechselnden Reihenfolgen vorgelegt. Die Studie sollte Aufschluss geben über die Erwartungen an den Elaborationsgrad der visuellen Kommunikation, die ein «normales`, durchmischtes Publikum mitbringt, d.h. Menschen ohne besondere gestalterische Vorkenntnisse, Personen in unterschiedlichen Lebensphasen, aus städtischen und ländlichen Gebieten, mit verschiedenen Ausbildungswegen und Berufen. Menschen also, die in ihrem Alltag 
tatsächlich mit den Kommunikationsmitteln konfrontiert sein könnten, die ihnen in der Versuchsanordnung vorgelegt wurden. Welche gestalterischen Maßstäbe setzen diese Testpersonen an die visuelle Kommunikation in den Bereichen Lokalpolitik und Gemeinwesenarbeit an? Welche Anforderungen an die Qualität, Professionalität und technische Ausarbeitung bringen sie mit? Unterscheiden sie sich in ihren Urteilen - und spielen dabei Herkunft, Ausbildung, Alter, Geschlecht oder politische Gesinnung eine Rolle? Wie reagieren die Befragten auf selbstgemachte, imperfekte, wenig elaborierte Gestaltungsformen? Ab wann gilt ihnen ein Artefakt als zu wenig professionell oder sorgfältig ausgearbeitet? Und bei welcher Variante ist es für sie vielleicht «zu viel des Guten»?

Die Auswertung der Wirkungsstudie erfolgt für jede Dreiergruppe nach demselben Prinzip: Zuerst werden der Gesamteindruck und die Einzelwirkungen ausgeführt, welche die Testpersonen mit den unterschiedlich elaborierten Varianten verbinden, wobei darauf geachtet wird, ob ihre Reaktion positiv oder negativ zu bewerten ist und welche Rolle die gestalterischen Elaborationsmodi und Imperfektionen dabei spielen. Anschließend werden Kriterien überprüft, die mit dem Elaborationsgrad eng verknüpft sind: Erkennbarkeit, Professionalität und Angemessenheit. Erkennen die Probanden aufgrund der Gestaltung rasch, worum es geht? Wirkt die Gestaltung professionell auf sie? Und halten sie das Kommunikationsmittel für angemessen gestaltet? Dabei interessiert auch, ob die Einschätzungen von Angemessenheit und Professionalität übereinstimmend ausfallen oder divergieren und ob zwischen den Befragten Konsens über eine Variante besteht oder ob sie diese kontrovers beurteilen. $\mathrm{Zu}$ jeder Variante wird schließlich die relative Einschätzung des Elaborationsgrads untersucht: Welche Variante wirkt auf die Befragten am professionellsten, welche am wenigsten professionell? Welche erscheint am angemessensten und welche am wenigsten angemessen? Auch hier werden Muster, Auffälligkeiten und Unterschiede herausgearbeitet.

\subsubsection{Wirkungen: Dilettantisch, durchschnittlich oder profiliert}

Gefragt nach dem Gesamteindruck und den Wirkungen, die ein Artefakt auf die Befragten hat, zeigt sich rasch, dass viele Testpersonen bereits Bezug nehmen auf das Kriterium der Angemessenheit («adäquat», «ok», «das passt») und der Professionalität («professionell», «nicht von einem Profi gemacht», «handgemacht», «gekonnt»), aber auch auf das Kriterium der gestalterischen Qualität ganz allgemein («gut», «schlecht»). Viele Aussagen hängen mit der Erkennbarkeit des Artefakts bzw. der Zuordnung zu einem bestimmten Genre oder Typus zusammen: «das kenne ich», «es wird sofort klar, was das ist», die Gestaltung sei «klassisch» oder «typisch für Wahlprospekte». Somit orientiert sich das Normalpublikum 
weitestgehend entlang derselben Matrix, wie sie aus der Expertenanalyse im Rahmen der Auslegeordnung abgeleitet werden konnte. Es wird jedoch im Einzelnen zu sehen sein, ob die Befragten die Begrifflichkeiten gleich anwenden wie zuvor die Gestaltungsexperten und ob es auch unter den Befragten Unterschiede im Verständnis dieser Elaborationskriterien gibt. Auf die Aspekte der Erkennbarkeit bzw. Zuordenbarkeit zu einem Gestaltungstypus oder -bereich, Professionalität und Angemessenheit wird im Anschluss an die genannten Wirkungen jeweils noch detailliert eingegangen. Oftmals werden unter den Wirkungen auch Vergleiche $\mathrm{zu}$ vorher präsentierten Varianten gezogen: Eine Variante wirke «billiger», «besser», «viel professioneller», «sonniger», «sympathischer» oder «viel schlechter» als die vorherige. Vielfach fallen ästhetische Urteile wie «schön», «hässlich», «gefällt mir», oder «das ist nicht mein Ding». Die vergleichende Sichtweise wird für jede Dreiergruppe in Bezug auf die Kriterien der Professionalität und Angemessenheit jeweils am Schluss des Abschnitts nochmals vertieft.

Variante «niedrig〉 - bieder, billig, dilettantisch: Die klassisch gestaltete, aber im Vergleich zum originalen BDP Wahlprospekt weniger elaborierte Variante «niedrig〉 (Abb. 74) konnte bei den befragten Testpersonen kaum punkten. Das elaborative Mindestmaß scheint hier unterschritten worden $\mathrm{zu}$ sein. In den Augen der Befragten tut der Wahlflyer zwar noch «seinen Zweck» als «konventioneller» Wahlprospekt «wie man ihn kennt», er wirkt auf sie jedoch «bieder», «spießig», «langweilig, «altmodisch» und «sehr ländlich». Die Gestaltung erscheint «hilflos», «naiv», «billig», «schlecht» oder gar «schlimm», zudem wird sie als «nicht aufgeräumt», «nicht klar angeordnet» oder «chaotisch» kritisiert. Damit verbunden sind ästhetische Urteile wie «hässlich», «wäh!» oder schlicht: «gefällt mir nicht». Bei jemandem würde der Prospekt «gleich im Müll» landen, ohne gelesen zu werden.

Besonders der gelb gerasterte Hintergrund mit Verlauf bzw. der «Gelbstich» kommt nicht gut an: Obschon er die Parteifarben aufnehme, sei er «kein Gewinn», er wirke «nicht ansprechend» oder «störend». Der gerasterte Hintergrund stelle einen bemühten und nicht mehr zeitgemäßen Versuch dar, gestalterisch «etwas Besonders zu machen». Die Rasterung verbreite zudem Unruhe und verstärke den unaufgeräumten Gesamteindruck; die gelbe Farbe rücke die darauf platzierten Kandidierenden in ein «schlechtes Licht» und lasse sie «unsympathisch» erscheinen. Das Gruppenbild wird denn auch als «steif» und «witzlos» wahrgenommen. Mehrere - ausschließlich weibliche - Personen nehmen die gelbe Farbigkeit des Prospekts jedoch positiv auf und halten sie für ästhetisch ansprechend, da von der gelben Grundstimmung eine «freundliche», «sonnige», «emotionale» Wirkung ausgehe. Das verwendete Papier wird - sofern explizit 
Gemeindewahlen Schüpfen

28. Oktober 2012

\section{Liste 3}

«Unsere Gemeinde liegt uns am Herzen, dafür setzen wir uns ein!»

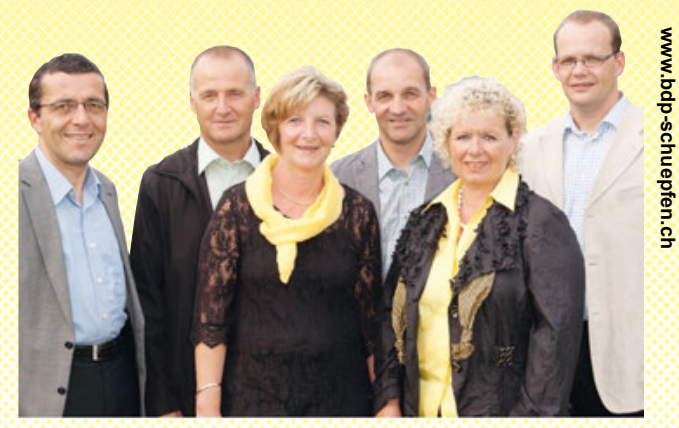

\section{Die BDP Schüpfen bewegt weiter!}
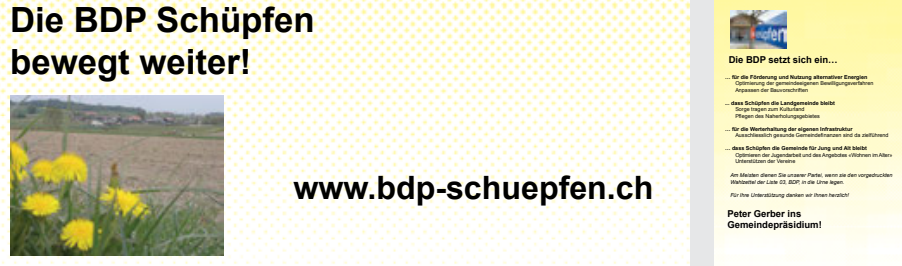

\section{Liste 3}
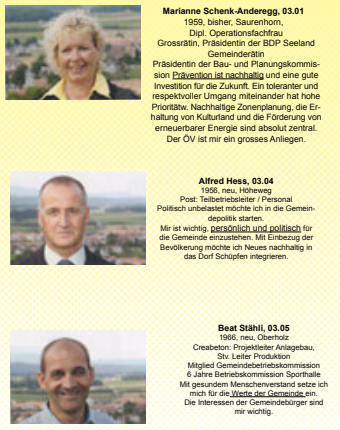

Gemeindewahlen Schüpfen
28. Oktober 2012
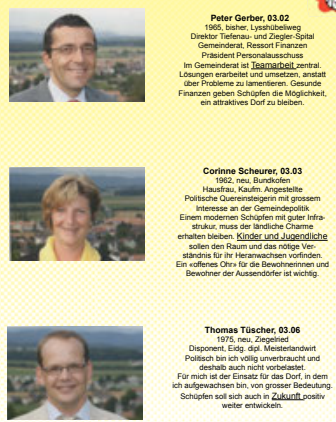

Die BDP Schüpfen bewegt weiter!

Abb. 74: Designvariante niedrig, Wahlprospekt BDP 
Gemeindewahlen Schüpfen 28. Oktober 2012

\section{Liste 3}

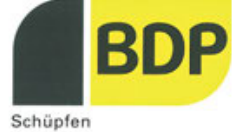

"unsere Gemeinde liegt uns am Herzen, dafür setzen wir uns ém!»
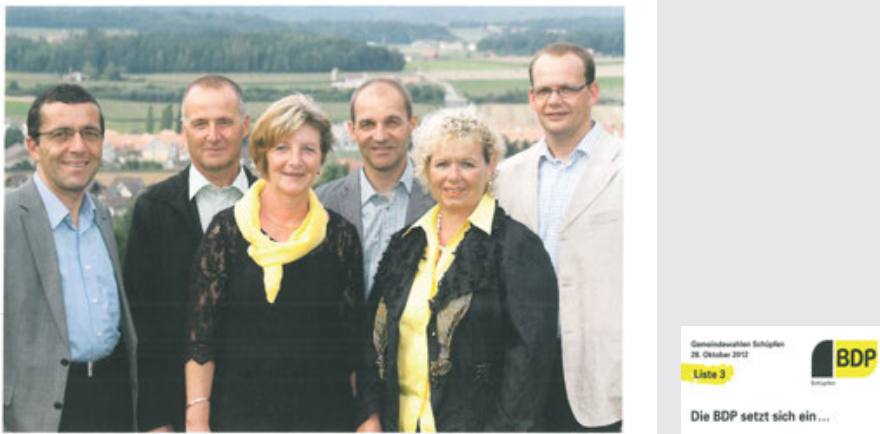

Die BOP setzt sich ein...

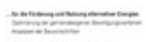

Die BDP Schüpfen bewegt weiter!

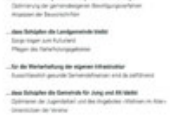

www.bdp-schuepfen.ch

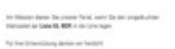

\section{Liste 3}


mumw bdp-schuepten ch
Gemeindewahlen Schúpten
28. Oktober 2012
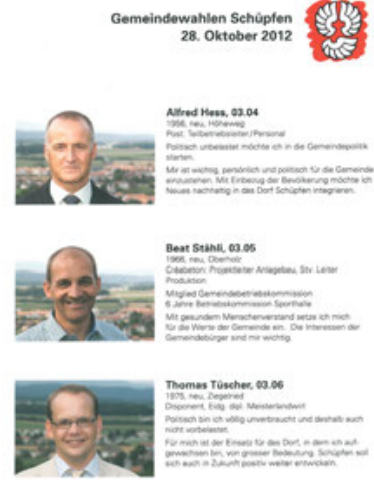

Thames Tüscher 0906
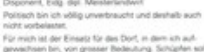

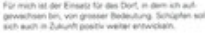

Abb. 75: Designvariante mittel, Wahlprospekt BDP (Original) 
erwähnt - als «billig» und «abstoßend» beurteilt: «Man möchte es nicht anfassen». Andere sehen die günstige Produktionsweise nicht als negativen Punkt. Gestalterische Unsauberkeiten und Fehler werden von den Befragten oft bemerkt und negativ beurteilt: Insbesondere die Gruppenfotografie sticht vielen als «schlecht freigestellt» oder «schlecht ausgeschnitten» ins Auge und die Fotos der Kandidierenden wirkten «zu dunkel», «unterbelichtet» bzw. seien von «schlechter Qualität», was teilweise als inakzeptabel beurteilt wird. Das Foto mit dem Löwenzahn (und etwas weniger auch das Bild des Bahnhofs Schüpfen hinten) sorgt bei vielen für Kopfschütteln: «Was soll das?». Das «Blümchen-Bild» wird als «bemüht», «künstlich», «hineingepflastert» und «überflüssig» betrachtet - nur eine Person sieht darin einen Ansatz, Wahlwerbung über die Gefühle zu betreiben. Ebenso überflüssig und «irgendwo platziert» erscheint den Befragten die zweifache Nennung der Webadresse der Partei auf der Titelseite. Auch typografische Mängel werden im Detail beanstandet: Der Slogan vorne werde durch einen «unmotivierten» Zeilenumbruch auseinandergerissen, auf den Innenseiten wirkten die zentrierte Schrift und die Unterstreichungen «störend», «hässlich», «dilettantisch». Der Text sei «überall» platziert bzw. «wild verteilt» worden und es fehle ein Satzspiegel, der die Ränder begrenze. Insgesamt würden übertrieben viele unterschiedliche Stilmittel und Auszeichnungen verwendet, was zu einem «Spiel mit allzu vielen Effekten» führe. Hinter diesen Effekten verschwänden wichtige Elemente wie das Parteilogo. Das Logo ist aus Sicht der Befragten überdies zu klein abgebildet und wirkt auf dem gelben Hintergrund zu wenig auffällig. Dieses Gelb auf Gelb wird als «unglücklich» bezeichnet und die Farbtöne «beißen sich».

Variante «mittel` (Original) - durchschnittliche Freundlichkeit: Die mittlere Variante, der Originalprospekt der BDP Schüpfen (Abb. 75), wird von den Befragten als «Mittelweg» wahrgenommen. In seiner Wirkung wird die Wahlwerbung in positiver Weise als «freundlich», «sympathisch», «ansprechend», «klar», «einfach», «sachlich», «sauber», «strukturiert», «nicht übertrieben», «nicht hochgestylt», «kurz und knackig», «schlicht» sowie «ländlich» beschrieben. Tendenziell negativ behaftet sind dagegen Wirkungszuschreibungen wie «langweilig», «vergilbt», «old-fashioned», «angestrengt», «nicht spritzig» oder «leicht unruhig». Der Prospekt wird unisono als «typisch», «klassisch», «durchschnittlich», «normal», «neutral», bzw. als «typisch bürgerlicher Wahlprospekt einer Landgemeinde» erkannt, wo «immer das gleiche Setting» vorgefunden werde: Der Prospekt ist «nichts Spezielles». Positiv werden das Weiß im Hintergrund und der ausreichende Weißraum vermerkt, was den Probanden vor allem im Vergleich zur niedrigen Variante ins Auge sticht. Das Format wird als «handlich» beschrieben, besonders auch verglichen mit der elaborierteren Variante. Einige meinen, 


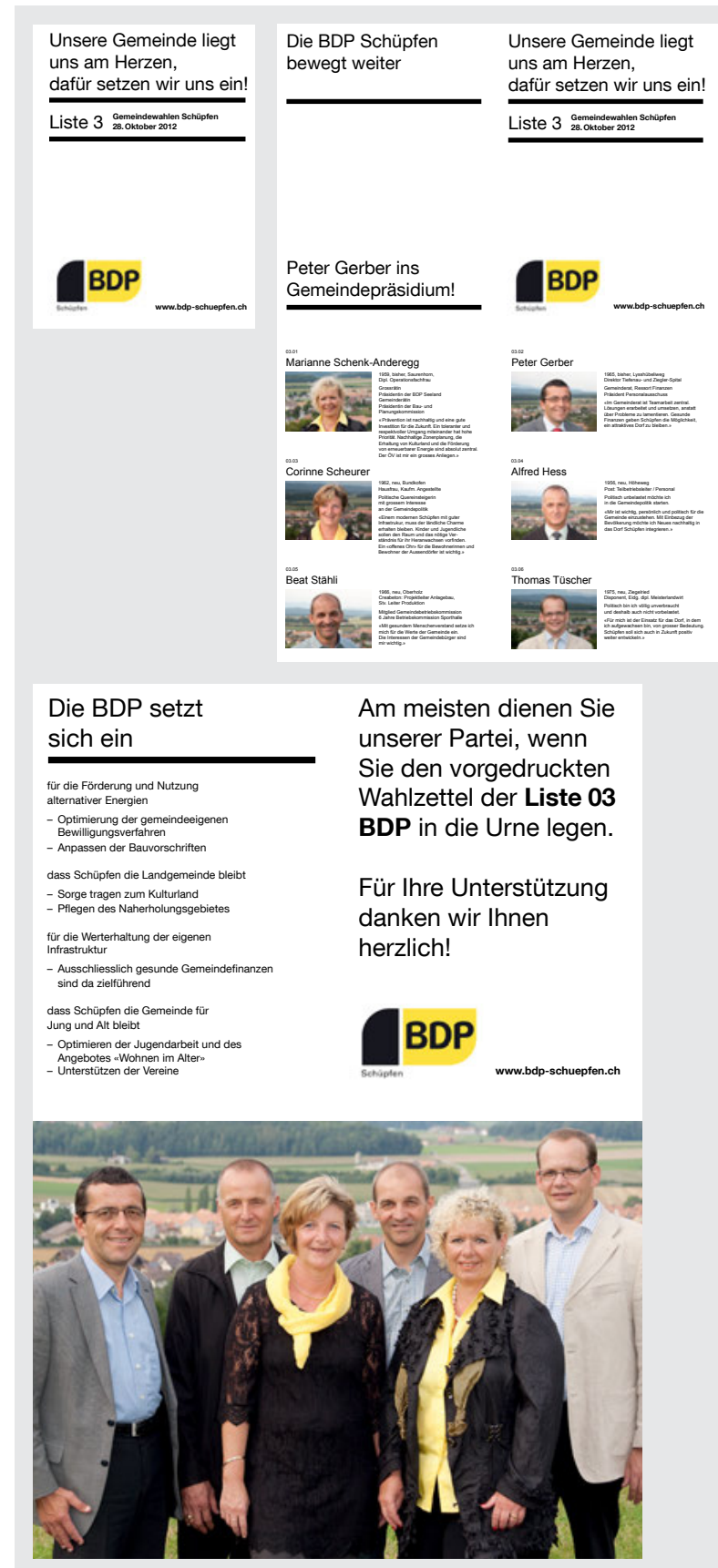

Abb. 76: Designvariante hoch, Wahlprospekt BDP 
sie würden diesen Prospekt aufgrund seiner Erscheinung gerne anschauen und aufgrund des knappen Texts auch lesen. Nicht bei allen weckt der Prospekt aber genügend Interesse, weil die Gestaltung «zu wenig ansprechend», «zu wenig interessant» sei. Eine Person bekundet große Mühe mit dem stereotypen «Zeigen von Köpfen» - dies könne nicht der Weg sein und sage nichts über die Kandidierenden aus. Die Wahlkommunikation müsse entweder «Leistung aufzeigen oder Sympathie wecken».

Im Detail werden vor allem die allzu zahlreichen Schriftbilder, Größen, Auszeichnungen, Ausrichtungen und Effekte moniert, die ein unruhiges und «unschönes» Gesamtbild beförderten. Die gelben «Pinselstriche» oder «Leuchtstiftmarkierungen», die auf dem Prospekt zur Hervorhebung von Textelementen eingesetzt wurden, führen $\mathrm{zu}$ auffallend konträren Wahrnehmungen. Die einen befinden, die «Filzstiftspuren» führten zu einer «frischen», «peppigen», «modernen» Wirkung und zu einer effektvollen und hilfreichen Hervorhebung - was zum Teil an eine "professionelle» Erscheinung und einen «überlegten» Auftritt gekoppelt wird. Die anderen finden jedoch gerade, die Striche ließen den Prospekt «unruhig», «hingeworfen» und «nicht professionell» erscheinen. Geschmacklich werden die «Schlieren» als unschön oder gar «schrecklich» empfunden. Die Hervorhebungen werden auch wegen ihrer «marketingmäßigen» Erscheinung abgelehnt oder weil sie «nicht zu verstehen» seien. Auch die vermeintlich von Hand geschriebenen Worte auf der Titelseite wirken nicht auf alle Versuchspersonen gleich. Einige empfinden ihre Wirkung als «persönlich» oder erkennen zumindest die damit verfolgte Absicht, den Betrachtern zu sagen: «Wir sind nahe bei euch» oder «das ist von Hand gemacht». Allerdings sei nicht zu übersehen, dass die Schrift am Computer erstellt worden sei. Beide Elemente, der pseudohandschriftliche, leicht nach oben aufsteigende Schriftzug und die gelben Markierungen, werden als Versuche gedeutet, «Frische» in die Gestaltung zu bringen oder «originell zu sein». Dieser Versuch gelingt jedoch in den Augen etlicher Probanden nicht oder erscheint ihnen «gezwungen». Besonders von einem gut ausgebildeten, städtisch geprägten Publikum werden diese technischen Effekte als «anbiedernd» und «altbacken» gedeutet, sie entsprächen nicht «den Vorstellungen von heutigem Design». Die Gestaltung erscheint diesen Personen, als wäre sie «in den frühen 1990er Jahren stehengeblieben», «wie von früher, aus den guten alten 90er Jahren» oder gar noch «von Ende der 1980er Jahre» - was dem Prospekt «auf kunstvolle Art» eine unprofessionelle Anmutung verleihe. Wenige kritisieren die schlechte Qualität von Druck und Papier und empfinden die Haptik des Hochglanzprospekts als «furchtbar».

Variante 〈hoch〉 - professionell, modern, reduziert, mit Profil: Der ausfaltbare und hochwertig produzierte Wahlprospekt 〈hoch〉 (Abb. 76), der vorne ohne ein 
Bild auskommt, innen jedoch ein ungewöhnlich großes Gruppenbild zeigt, wirkt auf viele Befragte positiv. Wie sich jedoch noch zeigen wird, ist er seiner professionellen Wirkung zum Trotz nicht das passendste Produkt zur Bewerbung einer konservativen Partei auf dem Land.

Die elaborierte Variante des Wahlprospekts erhält Wirkungszuschreibungen wie «(sehr) sympathisch», «(sehr) professionell», «ansprechend», «kommt gut rüber», «sehr gut gemacht», «adäquat», «einfach, klar, bodenständig», «erfrischend einfach», «übersichtlich», «gut lesbar», «schlicht», «klar» und "grafisch sauber», «sehr solide», «modern», «mit Profil», «hat eine Linie». Die Gestaltung zeige den Versuch, «modern zu wirken» und sich hervorzuheben: «Das will gelesen werden». Besonders das große, in guter Qualität und randabfallend gedruckte Gruppenbild wirkt auf viele Befragte «sympathisch», «gut», «plakativ» und wirkungsvoll - die Kandidierenden kämen so «besser zur Geltung» und ihr Charakter werde visuell vermittelt. Die ungewöhnliche Faltung wird von den einen als «lustige Idee» bezeichnet, den anderen ist das Format geöffnet fast zu groß, wieder andere sehen es als Plakat, das man aufhängen kann. Der größte Kritikpunkt ist jedoch, dass das Öffnen und Lesen bei dieser Variante zu umständlich sei. Das Aufklappen und viele Drehen finden verschiedene Probanden «nicht praktisch», «störend», »irritierend» und man wisse nicht, «wo man jetzt weiterlesen soll». Diese Personen mögen es «lieber kurz und kompakt» und «klassisch» (siehe auch unten: Erkennbarkeit). Die Falttechnik fällt einigen Probanden auch deshalb negativ auf, weil man je nach Öffnungsvorgang die Kandidierendenbilder zuerst verkehrt herum präsentiert bekommt. Während mehrere Personen vorne das Gruppenbild vermissen und die Erscheinung des Prospekts dadurch als «unpersönlicher» ansehen, empfinden andere es als gelungen, dass zuvorderst eine «sinnvolle und starke Aussage» stehe und nicht sofort die «Köpfe» zu sehen seien. Bei der elaborierten Variante wird zum Papier positiv vermerkt, dass man «etwas in der Hand» habe, «nicht nur einen Fresszettel». Das hochwertige, «nicht folierte» Papier wirke «natürlich», «ehrlich», «angenehm», «handfest».

Die Tatsache, dass auf der elaborierten Variante «wenige visuelle Reize» geboten werden («nicht zu viele Schriften», «keine Ausrufezeichen», «viel Weiß», «kein Titelbild»), wird von vielen als positiv, seriös und zum Inhalt passend wahrgenommen. Dieser Wahrnehmung entgegen stehen negative Einschätzungen: die Gestaltung wirke «fad», «trist», «wie eine Todesanzeige mit Trauerbalken» oder «wie eine Kernkraftwerkinformation» und sie sei «zu wenig emotional», es komme «keine Begeisterung» auf. Dieselben Merkmale - der viele Weißraum, die klare Struktur und die schwarzen Linien - können also beim Publikum positiv oder negativ aufgenommen werden. Manche beschreiben den Prospekt auch einfach in neutraler Weise als «aufgeräumt», «organisiert, «strukturiert» oder «nüchtern». 


\section{Einschätzungen zur Elaboration \\ Designvarianten Wahlprospekt}

rasch erkennbar professionell angemessen

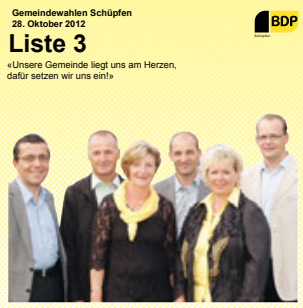

Die BDP Schüpfen

bewegt weiter!

www.bdp-schuepfen.ch
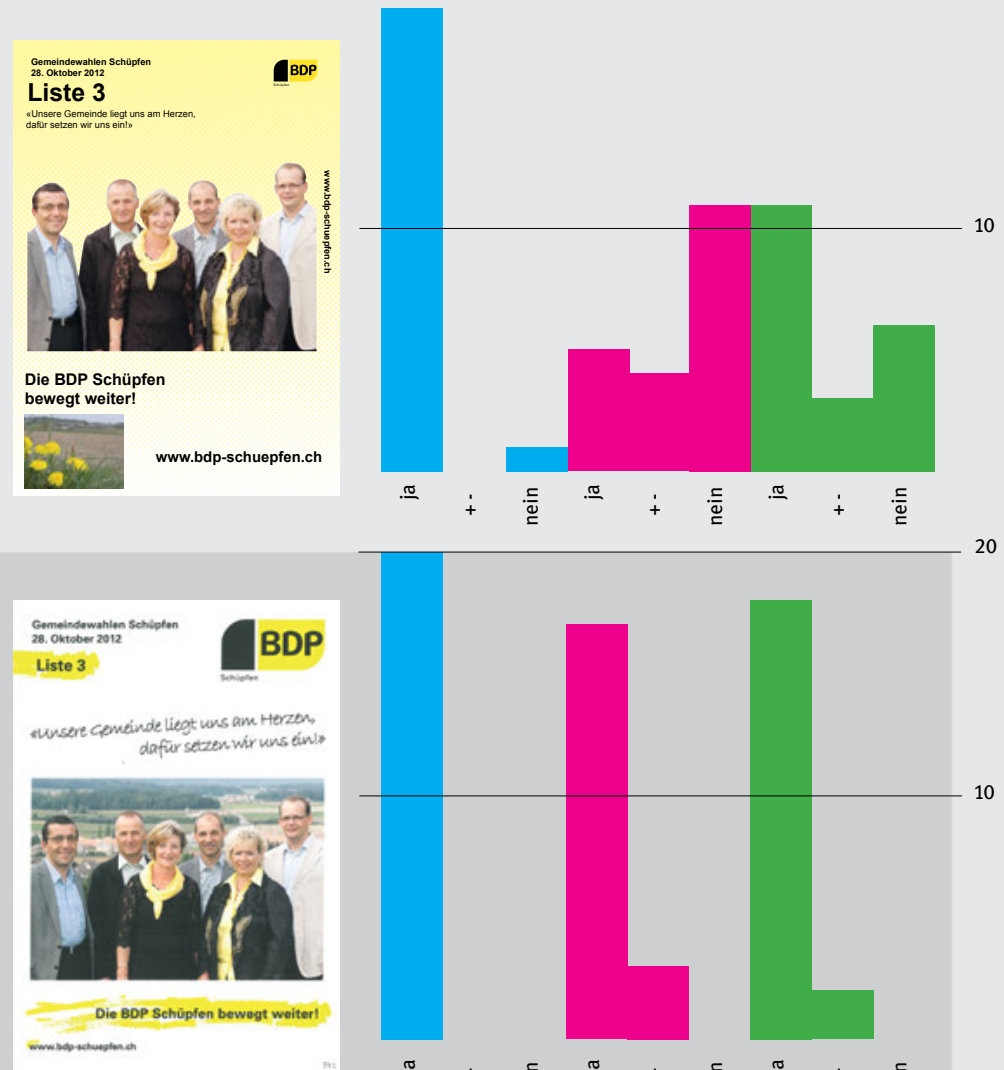

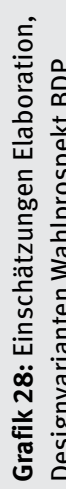

Unsere Gemeinde liegt uns am Herzen,

dafür setzen wir uns ein!

Liste $3 \underset{28.0 \text { kitober } 2012}{\text { Gemenewen Schüfen }}$
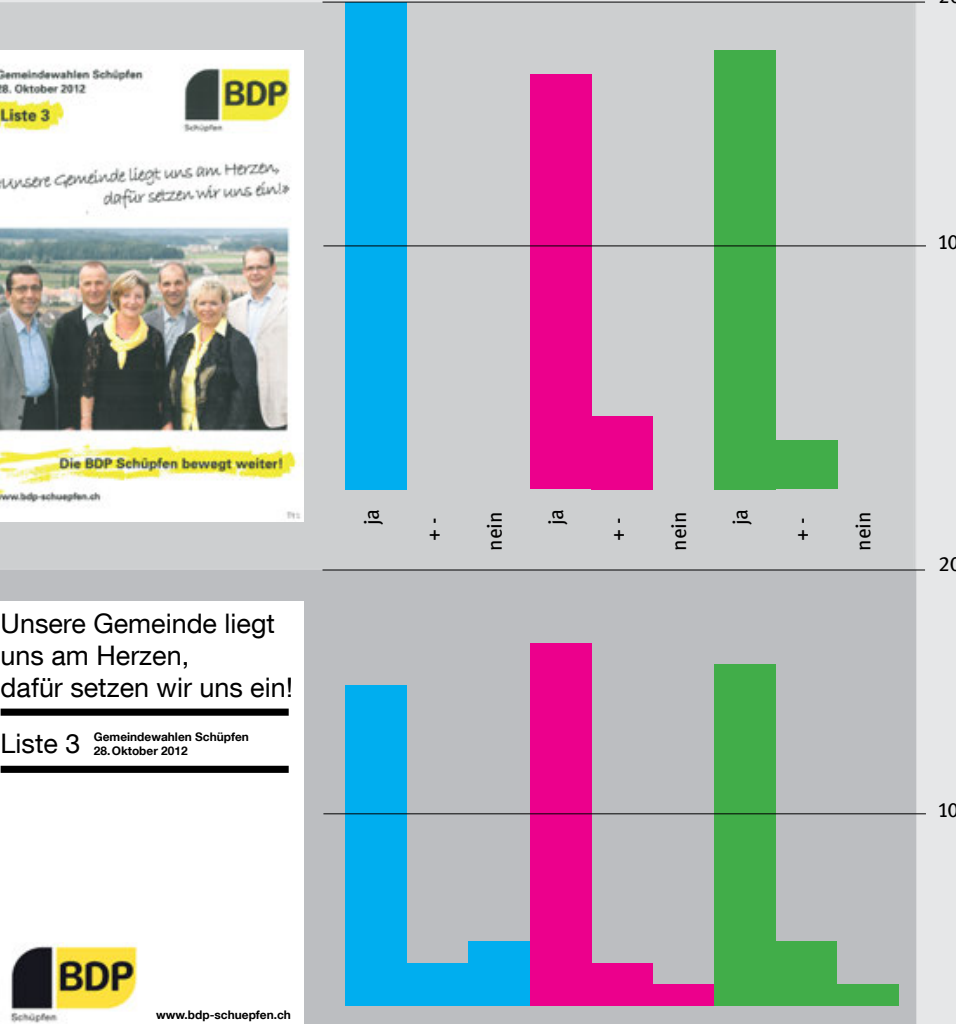

20

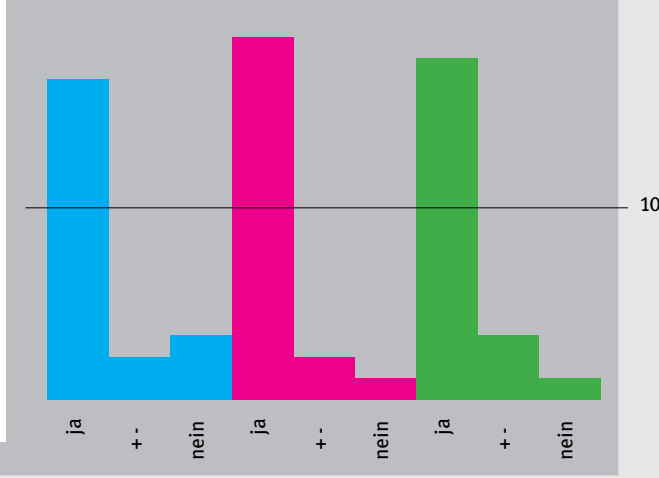




\subsubsection{Erkennbarkeit: Von glasklar bis unhandlich}

Beim Originalprospekt der BDP Schüpfen, also der mittleren Variante, gelingt die Erkennbarkeit des Prospekts als Wahlkommunikation einer bürgerlichen Partei im ländlichen Kontext aufgrund seiner Gestaltung am unmittelbarsten und raschesten. Hier wird sämtlichen Probanden «sofort klar», worum es geht und «mit wem man es zu tun hat» (vgl. Grafik 28 für eine Übersicht der Einschätzungen). Aber auch bei der niedrig elaborierten Variante ist dies bis auf einer Person allen sofort und ohne Umschweife ersichtlich. Beide Varianten entsprechen von der Aufmachung her dem typischen Wahlprospekt, «wie man ihn kennt» und somit auch rasch wiedererkennt. Die elaborierte Variante ist für die Befragten im Vergleich zu den beiden konventionell gestalteten Beispielen denn auch am wenigsten rasch als Wahlkommunikation erkennbar und die Ausgestaltung lässt für sie nicht immer sofort eine bürgerliche und ländliche Partei erwarten. Dennoch sagen immer noch drei Viertel, sie würden die Lage rasch, problemlos und «mit einem Griff» erfassen: Die «Message» sei klar und man sehe sofort, «was Sache ist». Für einige Personen ist die am stärksten elaborierte Variante jedoch «anspruchsvoller» und «umständlich», so dass sich die Orientierung etwas schwieriger gestalte. Besonders die aufwändigere Falttechnik lässt das Artefakt aus Sicht einiger Probanden unhandlich und weniger schnell erschließbar werden. Einigen ist die Einstiegsseite auch «zu diskret» und es fehlen ihnen «die Köpfe», um den Verwendungszweck sofort zu erfassen. Nur gerade drei Personen halten den Faltprospekt jedoch für schlecht erkennbar oder zuordenbar.

\subsubsection{Professionalität: Von keinem «Supergrafiker` gestaltet oder handgemacht?}

In Bezug auf die eingeschätzte Professionalität der Varianten liegen die mittlere und die hohe Variante weitgehend gleichauf (vgl. Grafik 28). Beide werden von einer überragenden Mehrheit, nämlich je siebzehn von zwanzig Personen, als professionell gestaltete Produkte eingeschätzt. Den niedrig elaborierten Prospekt dagegen hält rund die Hälfte der Befragten für nicht professionell und je etwa ein Viertel für semiprofessionell bzw. für professionell. Die Probanden sind sich also nicht ganz einig darüber, wie die Professionalität der niedrigen Variante einzuschätzen ist. Sicherlich wird die niedrige Variante als weniger professionell als die anderen Varianten betrachtet (die relativen Einschätzungen des Professionalitätsgrads folgen im Vergleichskapitel noch ausführlich). Verschiedene Zusatzaussagen der Befragten lassen Schlüsse darauf zu, was die Testpersonen mit ihrer Professionalitätseinschätzung jeweils meinen. Meistens wird die Ein- 
ordnung «professionell» mit der Annahme verbunden, dass die Variante «von einem Profi», also einem professionellen Grafikdesigner oder einer visuellen Gestalterin, designt wurde. Wird eine Variante dagegen als «nicht professionell» betrachtet, bedeutet dies aus Sicht der Testpersonen, dass die Gestaltung «zu Hause gemacht» oder «in Word erstellt» wurde, weshalb die nicht professionelle Gestaltung auch als «handgemacht» oder «dilettantisch» tituliert wird. Zudem wird unter dem Aspekt der Professionalität auch auf das Können des Urhebers verwiesen: Unprofessionell oder allenfalls semiprofessionell gilt ein Produkt den Testpersonen dann, wenn man diesem ansieht, dass der Gestalter «nicht Herr der Lage war» oder «Mühe hatte» bei der Ausführung. So wird der niedrigen Variante etwa beim Freistellen der Titelfotografie «mangelndes Können» unterstellt, was den Prospekt nur noch «semiprofessionell» erscheinen lasse. Der semiprofessionelle bzw. nicht mehr deutlich professionelle Bereich wird durch ein beschränktes, aber doch in bescheidenem Maß vorhandenes Know-how oder auch durch ungenügende Berufsausübung spezifiziert: So wirke die niedrige Variante zwar nicht wirklich professionell, «aber die Basis ist da», "aber ich könnte es nicht». Oder aber es könnte sich um Profiarbeit handeln, bei der jedoch ein «billiges Büro» oder zumindest «kein Supergrafiker» am Werk gewesen sei.

Die eingeschätzte Professionalität wird zudem mit dem Kriterium der Konzepthaftigkeit, Originalität sowie der gestalterischen Qualität insgesamt verknüpft. So wirkt die hohe Variante deshalb professionell, weil man ihr ansehe, dass sich der Gestalter «etwas überlegt» habe. Die Professionalität der mittleren Variante dagegen wird relativiert, indem sie als professionell, aber "phantasielos» bezeichnet wird oder von ihr gesagt wird, dass sie «keinen Designpreis gewinnen» würde. Auch wenn ein Prospekt seine Wirkungsintention in den Augen der Betrachtenden nicht oder nur unzureichend erfüllt, mindert dies den wahrgenommenen Professionalitätsgrad, so etwa bei der Variante «hoch», welche zwar professionell wirke, aber für eine Wahlwerbung zu wenig «appellativ» sei. Hierbei kommen bereits Aspekte der Angemessenheit zur Sprache, welche im nächsten Abschnitt ausführlicher behandelt werden.

\subsubsection{Angemessenheit: Gestaltung für das 〈Kaff〉 oder gestalterischer Anspruch?}

Bei der Einschätzung der Angemessenheit zeigt sich bei den Probanden ein leicht verschobenes Bild (vgl. Grafik 28). Liegt die hohe Variante - wie zu erwarten - in puncto Professionalität leicht vor der mittleren Variante, wird sie in Bezug auf die Angemessenheit von der mittleren Variante knapp überholt: Bis auf zwei Personen halten alle die mittlere Variante für angemessen und niemand findet sie 
gänzlich unpassend. Die Variante 〈hoch〉 dagegen erhält zwei positive Stimmen weniger und wird einmal als klar unangemessen bewertet. Obschon mehrheitlich als unprofessionell oder lediglich semiprofessionell eingestuft, wird die niedrige Variante von gut der Hälfte der Befragten als angemessen betrachtet - jedoch auch von fast einem Drittel als klar unangemessen. Dies zeigt, dass die Professionalität kein zwingendes Kriterium ist, um im Bereich der lokalpolitischen Kommunikation gelungen zu kommunizieren, und dass die Akzeptanz bei steigender Professionalität sogar wieder abnehmen kann. Bei der Beurteilung der Angemessenheit lassen sich zudem Grade unterscheiden: Die Urteile reichen von «absolut angemessen» bis hin zu «kann man so machen», «nicht ganz daneben», «nicht völlig verkehrt» oder «es reicht auch so».

Zur Bewertung der Angemessenheit berücksichtigen die Testpersonen verschiedene Faktoren. Zum einen tragen das Bedienen der Sehgewohnheiten und das Festhalten am «Standardwahlprospekt» bei den beiden klassischen Varianten zur wahrgenommenen Angemessenheit bei. Hierbei wird auch das Mittelmaß noch - oder gerade - als angemessen anerkannt. Mit der Variante «mittel> bewege man sich «in der großen Mitte», «im Durchschnitt». Auch Aspekte der technischen und materiellen Ausarbeitung, die nicht nur mit zeitlichem, sondern auch finanziellem Aufwand verbunden sind, werden ins Feld geführt. So wird bei der hohen Variante bemerkt: «da steckt sicher Geld dahinter» oder diese Variante wirke «eher teuer». In Verbindung mit örtlicher Wahlkommunikation werden allzu hohe Produktionsaufwände tendenziell als unangemessen erachtet - und eine gewisse Sparsamkeit als Tugend. Der mittlere Prospekt wird denn auch als passend beschrieben, «weil man nicht abartig viel Geld ausgeben soll für Wahlen».

Besonders zentral ist bei der Beurteilung der Angemessenheit der Wahlprospekte - ganz im Sinne des rhetorischen Aptum -, dass sie «den Zweck treffen» bzw. dass sie «erreichen, was sie wollen». Wahlkommunikation soll ihren Absender so zeigen, wie er es beabsichtigt und wie es zu ihm passt. Zur Angemessenheit gehört auch, dass die Wahlkommunikation «ihr Zielpublikum erreicht». Eine Variante gilt erst dann als angemessen, wenn die Probanden von ihr sagen können: «das ist, was ich brauche» oder «das ist, was die Wählerschaft will».

Dabei kann der Kontext die Ansprüche an den Elaborationsgrad auch herunterschrauben. So sei die mittlere Originalvariante zwar weder auffallend gut noch besonders originell gestaltet, jedoch sehr angemessen «für einen Gemeindeprospekt», «für eine kleine Ortspartei», «für ländliche Gemeindewahlen». Es gehe hier schließlich um Lokalwahlen, «nicht um den Bundesrat». Verschiedentlich wird deshalb sogar vermutet, die am wenigsten ausgearbeitete Variante könnte «zielgruppennah» sein - in einem Ort wie Schüpfen «könnte das ankommen» oder sie könnte zumindest ausreichen «für eine kleine Gemeinde und ein 
kleines Parteibudget». Allenfalls spiegle gerade die niedrige Variante die visuelle Sprache, welche «die Leute im Kaff» gewöhnt seien. Einige nehmen die handgestrickte Machart der niedrigen Variante als «ansprechender» und «emotionaler» wahr als die «durchschnittliche Langeweile» des mittleren Prospekts. Umgekehrt stellen verschiedene Personen die Angemessenheit der am stärksten elaborierten Variante in Frage, weil sie ihnen auf ein urbanes, eher linkes Publikum zugeschnitten zu sein scheint. Die Gestaltung sei «zu modern und nüchtern» für ein ländliches Publikum. Der Prospekt «könnte auch als SP-Prospekt durchgehen», da er zwar klassisch, aber nicht konservativ gestaltet sei und für eine bürgerliche Partei fast schon «zu frisch» daherkomme.

Als wichtiger Identifikationsfaktor wird das Gemeindewappen angesehen, das bei der Variante 〈hoch〉 aus Gründen der einheitlichen, geschliffenen Erscheinung weggestrichen wurde. Wer für Schüpfen die hohe Variante präferiert, begründet dies mit dem Argument «Schüpfen ist kein Loch» und habe also auch «einen gewissen Anspruch» an die Gestaltungsqualität. Im Hinblick auf den Absender wird die elaborierte Variante als angemessen bezeichnet, weil sie das Selbstbewusstsein der Partei in passender Weise spiegle: «Die BDP darf sich zeigen, das sind keine Nobodys». Am häufigsten führen solche Überlegungen zur kontextbezogenen Angemessenheit jedoch zum Urteil, dass die Elaborationsweise der mittleren Variante bzw. des Originals sowohl der bürgerlichen, gemäBigten Partei als auch dem eher ländlichen Kontext am besten entspreche. Der Prospekt sei «passend für eine Ortspartei» und lasse in seiner typischen, unverkennbaren Optik «keine Überraschung» darüber zu, wen man wähle. Die niedrige Variante dagegen repräsentiere den Absender nur unzureichend. Sie komme «zu wenig seriös» daher, was «schade» für die Partei sei: «Wenn ich bei der BDP wäre, würde ich mich besser verkaufen wollen». Aufgrund der unprofessionellen Gestaltung würde hier zudem eher «eine Randgruppenpartei oder ein politischer Einzelgänger» als Absender vermutet.

Mehrfach wird das Gruppenfoto, das auf allen Varianten zu sehen ist, auf seine Passung zum Kontext und Absender hin kommentiert: Grundsätzlich passe das Bild zur Partei, sei «landnah» und zeige im Hintergrund in passender Weise die «dörfliche Landschaft». Die gelbe Kleidung der beiden Frauen in den «LogoFarben» wird jedoch teils als übertrieben oder lachhaft angesehen: Die Damen hätten sich für das Foto offensichtlich «herausgeputzt», sähen aber aus «wie die Biene Maja» - was letztlich nicht zum ernsthaften Kontext der Lokalwahlen passe. Neben dem Bildmotiv tragen auch Faktoren der technischen Ausarbeitung dazu bei, ob das Resultat am Ende stimmig oder unpassend wirkt. Obschon alle Prospekte dasselbe Bild verwenden, wirkt das Foto auf dem Originalprospekt gegenüber dem freigestellten Bild der niedrigen Variante auf einige Befragte «ehrlicher» und «authentischer» bzw. «nicht so montiert». Wird der gestalterische 
Eingriff allzu offensichtlich, hemmt dies offenbar die Glaubwürdigkeit. Im qualitativ hochwertigen Großformat der elaboriertesten Variante wirkt die Gruppe auf die Testpersonen «charaktervoll», auf dem Original dagegen «etwas bieder» und in der niedrigen Variante sogar «unseriös» und «unsympathisch». Ein und dasselbe Bild kann also je nach Einbindung, Bearbeitung und Elaborationsgrad unterschiedliche Wirkungen entfalten und somit in seiner Angemessenheit variieren.

\subsubsection{Zu elaboriert? Die Varianten im Vergleich}

Bei der relativen Einstufung der Elaborationsvarianten des BDP-Wahlprospekts zeigt sich unter dem Aspekt der Professionalität ein klares Bild: Bis auf zwei Personen halten alle Befragten die elaborierteste Variante auch für die professionellste - wobei fünf davon sie zusammen mit der mittleren Variante auf eine Stufe setzen (vgl. Grafik 29). Die mittlere Variante wird zweimal allein an die erste Stelle gesetzt und fünfmal zusammen mit der Variante «hoch〉. Die Einordnung der niedrigen Variante ist deutlich: Sie wird von neunzehn der zwanzig Befragten als die am wenigsten professionelle Variante erachtet und steht kein einziges Mal an vorderster Position. Während die hohe Variante auch einmal ganz am Schluss steht, wird die mittlere Variante hier nie genannt. Die häufigste Reihenfolge ist bei der Professionalität 〈hoch - mittel - niedrig〉 - wie dies aufgrund der Elaborationsmerkmale und Wirkungshypothesen auch zu erwarten war. Betrachtet man dagegen die Angemessenheit, so kommt diese Reihenfolge weniger oft vor und sie wird von der Anordnung «mittel - hoch - niedrig〉 abgelöst. Anders als bei der Professionalität wird die mittlere Variante am häufigsten an die erste Stelle der Angemessenheit gesetzt. Die Variante «hoch〉 erhält zwar immer noch von der Hälfte der Testpersonen den ersten Platz, teilt diesen jedoch viermal mit der mittleren Variante und wird gleich dreimal als die am wenigsten angemessene Variante (dis-)qualifiziert. Somit schiebt sich die mittlere Variante in puncto Angemessenheit mit kleinem, aber deutlichem Abstand vor die hoch elaborierte, als professioneller eingestufte Variante. Damit bestätigt sich, dass die wahrgenommene gestalterische Professionalität nicht unbedingt mit der Akzeptanz einer Gestaltungsvariante übereinstimmen muss und dadurch nicht zwingend gilt: 〈je professioneller, desto gelungener`. Die Einschätzungen der Befragten zu den drei Beispielvarianten legen zudem nahe, dass in der lokalpolitischen Kommunikation - zumindest für einen wesentlichen Teil der Betrachter - hoch elaborierte Gestaltung weniger angemessen ist als weniger ausgefeilte, mittelmäßige Gestaltung. Zwar wird selbst für die politische Kommunikation in einer ländlichen Gemeinde wie Schüpfen ein professionelles Elaborationsniveau verlangt, 





doch gibt es auch eine Grenze, ein «Zuviel» an Elaboration, jenseits deren die Gestaltung wieder auf Ablehnung stößt.

Es lohnt sich, neben der Gesamteinschätzung der Varianten bezüglich Professionalität und Angemessenheit auch nach auffälligen Mustern bei den einzelnen Testpersonen zu suchen, welche in Grafik 29 nicht erkennbar sind. Dass die mittlere Variante mehrfach auf die gleiche Professionalitätsstufe gestellt wird wie die elaborierte Variante, hat nach Aussagen verschiedener Befragter nicht unbedingt damit zu tun, dass sie diese für technisch gleich gut ausgearbeitet halten, sondern damit, dass sie den Faktor Angemessenheit bereits bei der Professionalität mitberücksichtigen. Professionalität und Angemessenheit werden von ihnen nicht strikt voneinander getrennt. Diese Tatsache äußert sich auch darin, dass ein Großteil der Personen für die relative Einschätzung der Professionalität dieselbe Reihenfolge verwendet wie bei der Angemessenheit: Was am professionellsten eingestuft wird, ist für sie auch am angemessensten und das Angemessenste ist zugleich auch das Professionellste. Tatsächlich hat rund die Hälfte der Befragten für beide Beurteilungen exakt die gleiche Reihenfolge gewählt und bei einem knappen Drittel sind sich diese Anordnungen zumindest noch ähnlich.

Könnten die unterschiedlichen Verfahren bei der Klassifizierung der Varianten auf Unterschiede im Bildungsniveau oder Wohnort der Befragten zurückzuführen sein? Differenzieren Personen mit niedrigerem Bildungsniveau oder Menschen auf dem Land weniger in Bezug auf Designaspekte? Oder präferieren sie eher die weniger elaborierte Grafik? Werden Gestaltungselemente, die von einem urbanen und gut ausgebildeten Publikum als gesucht oder anbiedernd betrachtet werden, von diesen Personen vielleicht gerade als Professionalitätsmerkmale gedeutet? Tatsächlich zeigt sich, dass Personen mit niedrigerem Bildungsstand mehrheitlich dieselbe oder eine ähnliche Reihenfolge bei den Aspekten Professionalität und Angemessenheit wählen und auch Fachhochschulabgänger wählen meistens für beide Seiten dieselbe Anordnung. Bei den Universitätsabsolventen dagegen wählt nur gerade eine Person dieselbe Einstufung bei der Professionalität und der Angemessenheit, während der Rest diese leicht variiert oder die Reihenfolge sogar komplett anders einschätzt. Diese differenzierende Sicht berücksichtigt die Möglichkeit, dass professionellere Gestaltung, im Sinne von technisch versiertem, hochwertig umgesetztem Design, nicht zwingend bessere Gestaltung, d.h. für den verfolgten Zweck passendere Gestaltung, sein muss.

Die Uniabgängerinnen und -abgänger überlegen sich bei der Beurteilung der Angemessenheit der lokalpolitischen Designvarianten, was ein ländliches, konservatives, tendenziell weniger gut ausgebildetes Zielpublikum ansprechen könnte. Dies führt dazu, dass praktisch alle die mittlere Variante als die angemessenste wählen, obschon diese Variante ihnen persönlich oft nicht gefällt und sie diese ohne Ausnahme für weniger professionell halten als die elaborierte 
Variante. Der einzige Promovierte im Testpublikum wählt unter Berufung auf das Aptum als einzige Testperson sogar die niedrige Variante als die angemessenste. Überraschenderweise ist es jedoch keineswegs so, dass bei den Befragten die Personen mit niedrigerem Bildungsgrad bzw. jene Personen, welche in ländlichen Gebieten wohnen, die mittlere Variante für angemessener oder professioneller halten. Tatsächlich ist unter den Befragten dieser Gruppen die Quote jener, welche die elaborierteste Variante nicht nur für die professionellste, sondern auch für die angemessenste halten, deutlich höher als bei den Personen mit Uniabschluss. Die Personen mit tieferem Bildungsniveau, die öfter auch auf dem Land oder in der Agglomeration wohnen, schätzen die Variante 〈hoch〉 gleich oft als die angemessenste Variante ein wie die mittlere. Die mehrheitlich urban angesiedelten Akademiker hingegen schätzen die mittlere Variante dreimal so oft als angemessenste Variante ein.

Wie ist dieser Unterschied zu deuten? Projizieren die 〈Intellektuellen〉 eine Präferenz in das «normale Volk», die weniger gut ausgebildeten Schichten bzw. die konservative Landbevölkerung hinein, die so gar nicht existiert? Ist der Anspruch an gestalterische Qualität und Professionalität bei diesen Personen höher als vermutet wird? Wird der Landbevölkerung unterstellt, dass sie «gute〉 Gestaltung nicht zu erkennen vermag und falls doch, diese nicht akzeptieren würde? Diese Fragen werden noch virulenter, wenn man sich vor Augen führt, wie jene Personen, die sich selbst politisch in der Nähe der BDP verorten, die Varianten beurteilen. Alle Befragten, welche sich nahe bei der BDP sehen, bewerten die Variante 〈hoch〉 als die angemessenste. Je weiter die Personen sich dagegen von der Partei entfernt fühlen, desto eher wird zugunsten der mittleren Variante votiert. ${ }^{1}$ Das ist ein verblüffender Befund, der jedoch angesichts der kleinen Testgruppe nicht weiter ausgedeutet werden kann. ${ }^{2}$

1 Während die Personen, die der Partei nahe stehen, im Verhältnis von 3 zu 1 die elaborierteste Variante bevorzugen, ergibt sich bei jenen, die sich politisch weit weg von der BDP sehen, ein umgekehrtes Verhältnis von 3 zu 1 für die mittlere Variante. Bei den indifferent oder wenig entfernt Positionierten sind die Präferenzen bezüglich der Varianten «hoch` und «mittel` in etwa ausgewogen. Noch ausgeprägter zeigt sich die Umkehrung bei den potenziellen BDP-Wählerinnen und -Wählern: Wer auf die Frage «Könnten Sie sich vorstellen, jemanden von der BDP zu wählen?〉 mit 〈Ja` antwortete, hielt mit $4 \mathrm{zu} 1$ die Variante «hoch〉 für die passendste, wer «Nein` sagte, erachtete ebenfalls im Verhältnis $4 \mathrm{zu} 1$ die mittlere für die angemessenste. Bei «Vielleicht` steht es noch 2 zu 1 für die mittlere Variante.

2 Andere Merkmale wie Geschlecht, Alter oder Beruf der Probanden fördern dagegen keine auffallenden Unterschiede oder Gemeinsamkeiten in den Einschätzungen zutage. 


\subsection{Resultate Designvarianten Aushang Mädchentreff}

\subsubsection{Wirkungen: Zwischen improvisiert, niederschwellig und seriös}

Variante «niedrig〉 (Original) - froh und spontan oder nachlässig? Die niedrige Originalvariante des Aushangs für den Berner «Moditreff〉 (Abb. 77), die als Ausgangsbeispiel für die beiden elaborierteren Varianten genommen wurde, erscheint den Befragten zwar komplett dilettantisch gemacht, ist für viele aber gleichwohl passend für die Bewerbung eines Mädchentreffs. Wie schon in der Expertenanalyse führt das Beispiel zu gegensätzlichen Wirkungen bei den Befragten. Die Mischform aus «Flyer und Aushang» wird als typische «Laiengestaltung» bzw. «selbstgemachte» oder «selber gebastelte» Gestaltung beurteilt, «wie man sie in diesem Bereich eben so macht» bzw. «was man so macht, wenn man kein Equipment hat.» Der Aushang komme daher «wie bei den Pfadfindern», wirke «nicht allzu aufwändig» und sei «klassisch» für den Freiwilligenbereich. Es wird angemerkt, dass hier offensichtlich jemand «Freude am Gestalten» habe oder versucht habe, «alles interessant $\mathrm{zu}$ gestalten», wobei das Resultat «einigermaßen übersichtlich», «ansprechend», «recht gut», «simpel und klar», «ok» sei. Die laienhafte Gestaltung könne gerade dazu führen, dass der Flyer sein Publikum erreiche: «Man schaut hin, weil es nicht professionell gemacht ist». Jemand vermutet, die Gestaltung könnte «von Gleichaltrigen für Gleichaltrige» gemacht worden sein. Der originale 〈Moditreff〉-Zettel zaubert etlichen Betrachtern ein Schmunzeln aufs Gesicht oder verursacht ein «Jöö» bzw. einen NiedlichkeitsEffekt - er wirkt «herzig», «niedlich», «fröhlich», «herzlich», «sympathisch», «lustig». Besonders tragen zu dieser Wirkung die bunt und von Hand angemalten Symbole bei, die offenbar «schnell angekritzelt» wurden. Einige halten die bunte Ausgestaltung für «eine coole Idee», sie bringe etwas «Verspieltes» hinein. Ohne diese Farbtupfer wäre die Gestaltung für sie «langweilig». Anderen erscheinen die Motive und ihre ungelenke Bearbeitung «zu kindlich», sie wirken «wie von Kindern gemalt», «wie im Kindergarten», «zu wenig erwachsen» - besonders weil im Treff ja auch ernsthafte Teenageranliegen thematisiert würden.

Verschiedenen Befragten gefällt die Gestaltung des Aushangs allerdings überhaupt nicht. Sie ist ihnen selbst für eine Laiengrafik zu unsorgfältig gestaltet und wirke «allzu einfach», «lieblos», «unmotiviert», «im negativen Sinn selbstgebastelt», «schwabbelig», «schlecht lesbar», «wirr», «wild gewachsen», «ein Riesendurcheinander», «ziemlich schlimm». Das Resultat sei «noch wordiger als Word». Gar «schludrig» erscheinen die vor dem Kopieren von Hand hinzugefügten Textelemente, die Punkte und der Pfeil, die nicht einmal klar einem Angebot zuzuordnen seien («Was soll das?»), aber auch die «unsauber» und «hässlich» ausgemalten Formen. Das Logo aus «Schattenschrift» wird als 


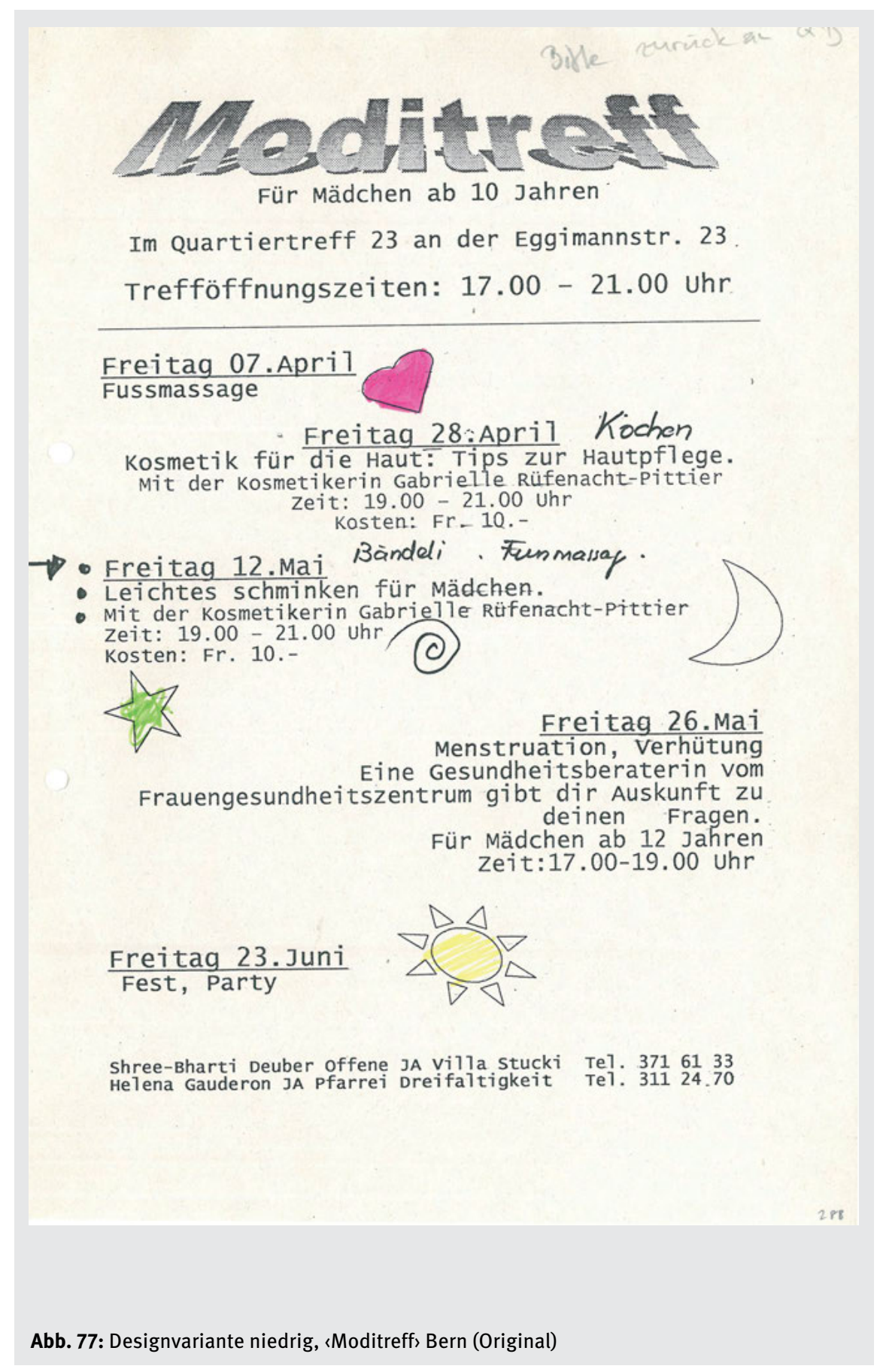


«kurios» oder ganz einfach als «schlecht» und «abschreckend» bezeichnet: So etwas könne man «nicht bringen» - auch wenn der Titel so immerhin klar heraussteche. Die Schreibmaschinenschrift und die «Word-Art»-Technik des Titels führen dazu, dass die Gestaltung von manchen als «altmodisch» oder «wie in den 1990er Jahren stehengeblieben» gesehen wird. Die Schriftgestaltung wird als eine «seltsame Mischung aus Schriften, Größen, Fehlern, Leerschlägen, Abständen» beschrieben und von jemandem gar als «grauenhaft» beurteilt. Aufgrund der uneinheitlichen Anordnung, Folge und Ausrichtung des Texts, wegen «zu wenig Zeilendurchschusses» bzw. zu enger Zeilenabstände fließe «alles ineinander» und wirke die Gestaltung «verwirrend» bzw. «sehr unübersichtlich». «Man muss sehr genau schauen, worum es geht». Auch das viele Schwarzweiß wird bemängelt, was den Aushang «fad» und «wie eingeschlafene Füße» wirken lasse. Die Druckqualität sei ausgesprochen schlecht. Jene, welche die Gestaltung für zu wenig elaboriert halten, ziehen das Fazit: «Mit wenigen Mitteln hätte auch ein Nichtprofi mehr herausholen können».

Variante «mittel` - cooles Chaos: Die mittlere Variante (Abb. 78), die versucht, die laienhaften, spontan und engagiert wirkenden Elemente aus der niedrigen Variante in ein leicht professionelleres Design zu übertragen, wird von den Befragten ebenfalls kontrovers aufgenommen. Für einige ist dieser Versuch erfolgreich, so dass der Aushang auf sie «farbig», «frech», «witzig», «lustig», «herzig und cool» wirkt. Sie befinden, das Resultat sehe «gut aus», sei «sehr cool umgesetzt», «könnte als Plakat Interesse wecken» und spreche die Zielgruppe der «Teenies» an. Andere halten die Gestaltung zwar für ansprechend und wirkungsvoll, aber nicht unbedingt geeignet für einen Mädchentreff, sondern eher «für ein Designermagazin». Nochmals andere halten das Produkt für «nicht ansprechend», «nicht attraktiv» und ihnen gefällt das gestalterische Ensemble nicht. Sie erachten es aufgrund der verschiedenen ineinander «verschachtelten» Ebenen sowie der fehlenden Gewichtung und Redundanz der Inhalte als «chaotisch», «ein Riesenchaos», «nicht harmonisch», «anstrengend zum Anschauen», «unübersichtlich», «unstrukturiert», «zu wild», «zu verworren», «total konfus» «unleserlich», «unklar» oder nur mit «Insider-Kenntnissen» zu verstehen: «Die Message ist versteckt». Bei einem der Befragten, der selbst eine Tochter hat, die einen Mädchentreff besucht, stößt die Variante auf Ablehnung. Auf eine mehrfache Mutter und Großmutter dagegen wirkt die Gestaltung des Aushangs «absolut treffend». Das einzige Teenager-Mädchen unter den Befragten findet den Flyer «gut», und sie würde ihn «sicher anschauen». Positiv fallen der jungen Frau besonders die bunten Farben auf, sie kritisiert jedoch die Lesbarkeit und den Suchaufwand, so dass sie dieser Variante am Ende die niedrige sowie auch die professionellere Variante vorzieht. 


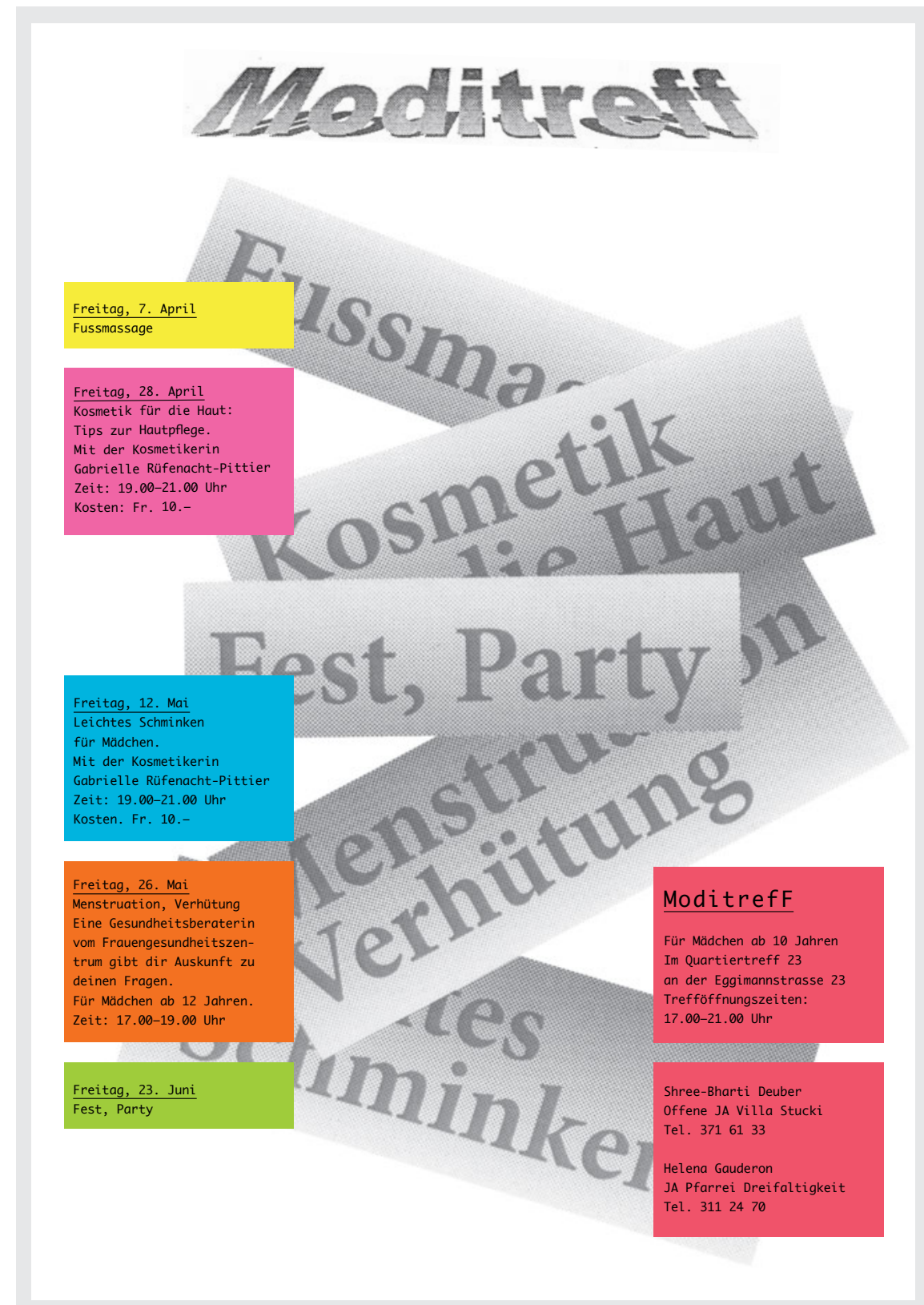

Abb. 78: Designvariante mittel, 〈Moditreff〉Bern 
Auch die einzelnen Gestaltungsmerkmale, die auf dem Aushang eingesetzt wurden, führen $\mathrm{zu}$ gegensätzlichen Einschätzungen: Die Kombination von Farbblöcken und grau-schwarzen Elementen erscheint den einen in Ordnung, für andere ergibt sich daraus eine «ermüdende Kombination von 3D und flach». Die wild übereinander geschobenen Balken mit den «Schlagwörtern» in der Mitte vermitteln einigen Testpersonen, wie intendiert, eine gewisse «Niederschwelligkeit» und Augenfälligkeit des Angebots, da sie auch als «Aufhänger» dienten: «Das könnte das Interesse der Mädchen wecken» und sie "gut ansprechen». Gerade das «Chaotische und Unstrukturierte» entspreche der Art der Mädchen, sie würden sehen: «Hier tobt sich jemand aus». Andere wiederum empfinden gerade die Ausgestaltung des Mittelteils als unleserlich und «schrecklich». Tendenziell positiv eingeschätzt werden die «knalligen» Farben bzw. die bunten Kästen mit den Informationen zu den einzelnen Veranstaltungen. Dadurch wirke das Ganze ansprechend und als «Eyecatcher», der zum Lesen anrege. Auf einige wirkt der Stil insgesamt «verstaubt», «wie aus den 90er Jahren», für andere wiederum sieht das Plakat aus wie «ßBlick〉-Schlagzeilen» ${ }^{3}$ oder wie eine «Reklame». Besonders das Logo fällt für sie aus der Art, da es klar aus einem Laienkontext stamme. Als Plakattitel dürfe das Logo ruhig stärker und in Farbe «rauspoppen». Falls man es für wiederkehrende Veranstaltungsprogramme beibehalte, könne dieses Logo für andere jedoch einen «Wiedererkennungswert» bilden und gerade aufgrund seiner Unbedarftheit sympathisch und ansprechend wirken: «Ich wurde mit Word-Art groß: 3D und Schlagschatten. Das erinnert mich an meine Jugend.» Ebenfalls kontrovers wird die in den farbigen Boxen verwendete Schreibmaschinenschrift eingeschätzt: Wirkt diese Schrift auf die einen «cool», halten sie andere für verfehlt und in ihrer technischen Wirkung nicht für ein weibliches Publikum geeignet. Zwei Frauen um die dreißig befinden insgesamt, die Gestaltung «mache sie nicht an» bzw. sie würden aufgrund dieses Auftritts «nie hingehen» zu diesem Treff; zwei ältere ebenfalls weibliche Testpersonen dagegen meinen: «Das hätte mich angesprochen», «das könnte ziehen».

Ein Hauptunterschied lässt sich insgesamt zwischen jenen Befragten erkennen, welche die unübersichtliche Gestaltung der mittleren Variante für unzumutbar halten und jenen Personen, welche finden, auf einem Plakat für einen Mädchentreff müsse nicht alles lesbar sein, etwas «Quatsch» und Verspieltheit könne die Gestaltung für ein solches Angebot vertragen. Während erstere den Fokus auf die Verständlichkeit der Information und die Seriosität des Absenders setzen, scheinen letztere die gestalterische Spontaneität und Unbeschwertheit, aber auch die Niederschwelligkeit des Angebots, die durch die Gestaltung vermittelt werden, höher zu bewerten. In der Mitte liegen jene, welche das Grund-

3 Der «Blick» ist eine Schweizer Boulevardzeitung. 
konzept und die fröhliche Anmutung des Flyers für gut befinden, aber auf das «Chaos» gerne verzichten würden. Gewisse Irritationsmomente gehen auch auf den Versuch der mittleren Variante zurück, die verspielte, mädchenhafte Art des Originals aufzunehmen, indem laienhafte und selbstgemachte Elemente verwendet werden, diese jedoch durch eine professionellere Elaborationsweise $\mathrm{zu}$ verbessern. So erscheint einigen die Mischung aus «Profiaspekten» wie den farbigen Kästen und dem laienhaften «Word Art-Titel» seltsam. Die Gesamterscheinung ist für sie nicht so leicht einem Genre oder Bereich zuzuordnen wie die Originalvariante. Es ist also nicht ohne Weiteres möglich, ein laiengestalterisches Artefakt «einfach etwas professioneller» zu gestalten, um damit ein besseres Resultat zu erzielen. Immerhin scheint es der mittleren Version in ihrer Anlehnung an unprofessionelle Elaborationsformen zu gelingen, gestalterische «Stereotype zu untergraben» - was dem Plakat einen «urbanen» Charakter verleihe.

Variante 〈hoch > - ein Kompromiss von Spiel und Ernst: Die elaborierte Variante (Abb. 79), die den offiziellen Charakter des Treffs betonen, aber immer noch einen Hauch Mädchenhaftigkeit erhalten sollte, wird von den Testpersonen als «modern», «aktuell», «freundlich», «fröhlich», «herzlich», «cool», «witzig», «leicht» «angenehm» und zugleich als «gradlinig», «strukturiert», «aufgeräumt», «klar», «deutlich», «übersichtlich», «sehr lesbar», «kurz und bündig», «neutral» und «nicht übertrieben» beschrieben. Einigen «gefällt» die Gesamterscheinung bzw. sie halten die Variante für «schön», «gut». Das unter den Befragten einzige Mädchen der Altersgruppe findet, sie «hätte Lust hinzugehen», und verschiedene Eltern sagen, sie würden ihr Kind angesichts der Erscheinung des Plakats mit einem guten Gefühl zum Treff hinschicken. Auf andere wiederum wirkt die Gestaltung «kühl», «trocken», «zu geordnet» und «etwas leer». Einige finden, das Kleinplakat sehe aus «wie die Titelseite eines Magazins» oder aufgrund der «schlagzeilenhaft» aufgeführten Detailangaben zum Angebot «wie eine Zeitung». Durch die farbigen Symbole erhalte das Artefakt einen «Farbtupfer», etwas «Verspieltes», «Lustiges» und «Kindliches», das aber «nicht zu kindlich» wirke. Die Motive werden als «gute Details» beurteilt, die auch dazu dienten, die einzelnen Abschnitte $\mathrm{zu}$ trennen, das Layout $\mathrm{zu}$ «portionieren» und «pointiert» auszugestalten sowie die unterschiedlichen Angebote "piktogrammartig» erinnerbar $\mathrm{zu}$ machen. Nur für eine Person stellen diese Symbole einen bemühten Versuch dar, «locker zu wirken».

Durch die klare Hierarchie und Aufteilung der Informationen, das «durchgezogene System», den vielen Weißraum, die «luftige Typografie» und die großen Angebotstitel seien die einzelnen Punkte auch von weit her sichtbar und erhalte das Gesamte eine «plakativere» Wirkung - allerdings findet jemand den Abstand von Groß- zu Kleinschrift zu «krass». Einen zeitgemäßen Charakter erhalte der 


\section{moditreff frühling}

Freitag 07. April

\section{Fussmassage}

米

Freitag 28. April

Kosmetik

für die Haut

Tips zur Hautpflege. Mit der Kosmetikerin Gabrielle Rüfenacht-Pittier Zeit: 19.00-21.00 Uhr, Kosten: Fr. 10.-

\section{(2)}

Freitag 12. Mai

\section{Leichtes Schminken} für Mädchen

Mit der Kosmetikerin Gabrielle Rüfenacht-Pittier

Zeit: 19.00-21.00 Uhr, Kosten: Fr. 10.-

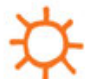

Freitag 26. Mai

\section{Menstruation, Verhütung}

Eine Gesundheitsberaterin vom Frauengesundheitszentrum gibt dir Auskunft zu deinen Fragen. Für Mädchen ab 12 Jahren. Zeit: $17.00-19.00 \mathrm{Uhr}$

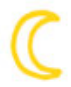

Freitag 23. Juni

Fest, Party

\section{moditreff}

Für Mädchen ab 10 Jahren

Im Quartiertreff 23

an der Eggimannstr. 23

Trefföffnungszeiten:

17.00-21.00 Uhr

Shree-Bharti Deuber Offene JA Villa Stuck Tel. 3716133

Helena Gauderon JA Pfarrei Dreifaltigkeit

Tel. 3112470

ณூת

Abb. 79: Designvariante hoch, «Moditreff〉 Bern 
Aushang vor allem durch die Titelgestaltung in Kleinschrift, welche aus dem 〈Moditreff» einen «Brand» mache. Die gewählte Schriftart und -stärke wirkt auf eine Testperson allerdings nicht «jung und zart», sondern «streng»: «Sie macht fast Angst». Als auffallend wird das rosa Herz in der rechten oberen Ecke bezeichnet. Dieses strahle eine gewisse «Wärme» aus und stehe stellvertretend «für alles», was den Treff ausmache. Durch den ebenfalls ins Auge stechenden Absenderblock mit dem Logo der Stadt Bern erhalte das Plakat eine «klare Zuordnung» zum Absender, was «praktisch» sei und zugleich auch mit einem «offiziellen», «amtlichen» und «seriösen» Charakter und «einer gewissen Strenge» verbunden wird. Von verschiedener Seite wird befürchtet, das Absenderlogo der Stadt könne die Mädchen vom Besuch des Treffs abschrecken, da dieses «uncool» und «nicht spontan» wirke und die Niederschwelligkeit des Angebots vermindere.

\subsubsection{Erkennbarkeit: Ordnungssinn versus Neuheitswert}

In puncto Erkennbarkeit schneidet die Variante «hoch klar besser ab als die beiden anderen, welche etwa gleichauf liegen (vgl. Grafik 30). Für rund drei Viertel der Befragten verrät die elaborierte Variante ihren Verwendungszweck rasch: Man sehe gleich bzw. verstehe von Anfang an, worum es gehe. Das Plakat vermittle «schnelle Infos», es werde «auf einen Blick klar, was hier in welchem Rahmen stattfindet». Der Rest hält die Variante nur für mittel bis schlecht erfassbar. Es werde auch nicht ganz klar, ob es sich um einen Flyer oder ein Plakat handle, und der Titel in Kleinschrift springe zu wenig ins Auge. Die beiden anderen Varianten erhalten vergleichbare Bewertungen: Bei beiden wird nur etwas weniger als der Hälfte schnell klar, wofür hier geworben wird. Für die Mehrheit sind die beiden Aushänge zum Mädchentreff in der mittleren und niedrigen Variante nur mittel bis schwer zu erfassen. Bei der mittleren Variante müsse man «nach den Informationen suchen» oder zumindest «gut hinschauen», doch sobald man die Titel in der Mitte überschaut habe, werde «das Gesamtkonzept klar». Bei der niedrigen Originalvariante wird rund einem Drittel «erst auf den zweiten Blick» klar, worum es geht und «was wann angeboten wird», ein Viertel kann sogar nur schlecht erkennen, wofür hier geworben wird. Für einige hängt diese Schwierigkeit bei der niedrigen Variante damit zusammen, dass das Programm «nicht plakativ» bzw. «zu diskret» gestaltet wurde. Auch die Informationen zum Absender seien zu wenig gut ersichtlich: «Wer leitet diese Gruppe?» Bei der hohen Variante werde dies hingegen sofort klar. Auffallend ist, dass die mittlere Variante stärker polarisiert als die niedrige: Beim offensichtlich in Laienmanier gestalteten Flyer nimmt die eingeschätzte Erkennbarkeit linear ab, bei der «verbesserten» mittleren Variante wird die Erkennbarkeit entweder als gut oder als schlecht eingeschätzt und 
etwas weniger als mittelgut. Dies könnte mit der bereits thematisierten Schwierigkeit zusammenhängen, dass die mittlere Variante Stilmittel der Laiengestaltung und professionelle Elaborationsmerkmale in neuer und ungewohnter Weise kombiniert, während die niedrige Variante klar der Laiengestaltung zugeordnet werden kann und die elaborierteste Version ein klassisches Schema der Profigestaltung verwendet.

\subsubsection{Professionalität: Unsorgfältige Laiengestaltung - oder jemand, der sich auskennt}

Befragt nach der Professionalität der drei Varianten, erhält - wie anhand ihrer Elaborationsmerkmale $\mathrm{zu}$ erwarten ist - die Variante 〈hoch〉 einen deutlichen Vorsprung vor den anderen beiden Varianten (vgl. Grafik 30). Während drei Viertel der Befragten die elaborierte Variante für professionell halten, sind es bei der mittleren noch knapp ein Drittel. Bei der niedrigen Variante ist es gerade umgekehrt. Hier sind gut drei Viertel der Meinung, es handle sich um nicht-professionelle Arbeit bzw. Laiengestaltung. Bei der hohen Variante wird meist angenommen, es «stecke ein Designer dahinter», aber auch hier halten drei Personen die Gestaltung für semiprofessionell und zwei gar für laienhaft: «Das war wohl keine Werbefirma, aber vielleicht jemand, der sich auskennt und das schon öfter gemacht hat». Bei der mittleren Variante sind sich die Befragten über die Professionalität nicht einig, so dass am Ende etwa gleich viele Personen die Gestaltung für professionell, semiprofessionell («da war jemand im Kurs») und laienhaft einschätzen. Auch dieser disparate Befund lässt sich vermutlich auf die unübliche Verbindung von laienhaften und professionellen Elaborationsmerkmalen zurückführen. Die niedrige Variante wird immerhin noch von drei Personen für professionell gehalten und von einer für semiprofessionell. Die klare Mehrheit hält die Gestaltung aber für «selbstgemacht», «am PC gebastelt». Die rasche Erkennbarkeit und Vermittlung der Botschaft gilt als ein Professionalitätsmerkmal, das die elaborierte Variante auszeichnet, jedoch bei den anderen vermisst wird; ebenso die «gute Druckqualität», welche ausschließlich bei der Variante 〈hoch〉 festgestellt wird.

Zudem hat sich gezeigt, dass auch bei der Beurteilung nicht-professioneller Gestaltung Elaborationsaspekte wie das Konzept und die technische Ausarbeitung eine Rolle spielen können, aufgrund deren die Gestaltung für mehr oder weniger dilettantisch bzw. fachmännisch gehalten wird. So wird etwa bei der niedrigen Variante die «Gestaltungsidee» als gelungen bezeichnet, der technischen Ausgestaltung sei jedoch zu wenig Sorge getragen worden. 


\subsubsection{Angemessenheit: Zu kindlich oder zu unterkühlt - Laiengestaltung könnte passen}

Im Vergleich zur Bewertung der Professionalität und Erkennbarkeit rücken die Gestaltungsvarianten des Mädchentreffs in Bezug auf die Angemessenheit deutlich näher zusammen (vgl. Grafik 30). So wird jede der drei Varianten von ungefähr der Hälfte der Befragten als angemessen bezeichnet. Die höchste Bewertung erzielt hier immer noch die Variante 〈hoch〉: Sie wird von knapp mehr als der Hälfte als angemessen bewertet und immerhin noch von fast einem Drittel als einigermaßen passend. Nur drei Personen halten sie für gänzlich unangemessen. Fast gleichauf liegen in puncto Angemessenheit die mittlere Variante und das Original. Sie werden von etwas weniger als der Hälfte für angemessen gehalten, allerdings auch von etwa einem Viertel für klar unangemessen. Im Gegensatz zur Professionalitätseinschätzung polarisiert hier die niedrige Variante etwas stärker, d.h. sie wird eher als klar unangemessen oder als klar angemessen angesehen, während die mittlere etwas mehr unentschiedene Einschätzungen erhält.

Relevante Kriterien für die Beurteilung der Angemessenheit sind auch beim Aushang aus dem Bereich der Gemeinwesen- bzw. Jugendarbeit Kontextfaktoren wie die Zielgruppe, der beworbene Anlass und der Absender: Besonders die Variante 〈hoch〉 wurde von vielen als «alters-» bzw. «zielgruppengerecht» bezeichnet. Einige sehen den «trockenen Ton» dieser Variante jedoch kritisch, da er der Zielgruppe der Mädchen nicht angepasst sei. Verschiedentlich wird das Produkt als «zu unterkühlt» oder «zu aufgeräumt», ja «fast schon zu professionell» erachtet, um die jugendliche Zielgruppe zu erreichen. Damit zeigt sich erneut, dass der Elaborationsgrad nicht nur als zu gering, sondern auch als zu hoch betrachtet werden kann: Nicht nur Mängel und Imperfektionen, sondern auch ein ‘Zuviel〉 in der Elaboration können zu Ablehnung führen. Selbst jene Personen, denen die elaborierte Variante persönlich gut gefällt, schränken mit Blick auf den Anlass und die Zielgruppe die Angemessenheit dieser Variante ein, weil sie vermuten, dass sie für die Mädchen «zu nüchtern» oder «zu wenig spielerisch» sein könnte. Andere führen wiederum an, dass die sachliche, offizielle Gestaltungsweise der elaborierten Variante die Eltern ansprechen könnte, welche auch als Teil der Zielgruppe gelten müssten. Denn als Erziehungsberechtigte entschieden die Eltern mit, was ihre Töchter im Teenageralter in ihrer Freizeit unternähmen. Als passend für die Zielgruppe dagegen werden bei der elaborierten Variante die bunten Symbole betrachtet - ohne welche die Gestaltung «zu klassisch» oder «zu kühl» für die angesprochenen Mädchen sei. Dank dieser Symbole schlägt das Plakat in den Augen verschiedener Testpersonen auch die «Brücke» von der Ansprache der Eltern zu jener der Mädchen. 


\section{Einschätzungen zur Elaboration}

Designvarianten Mädchentreff rasch erkennbar professionell angemessen

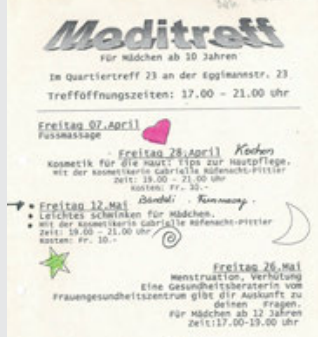

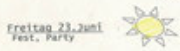

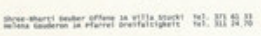

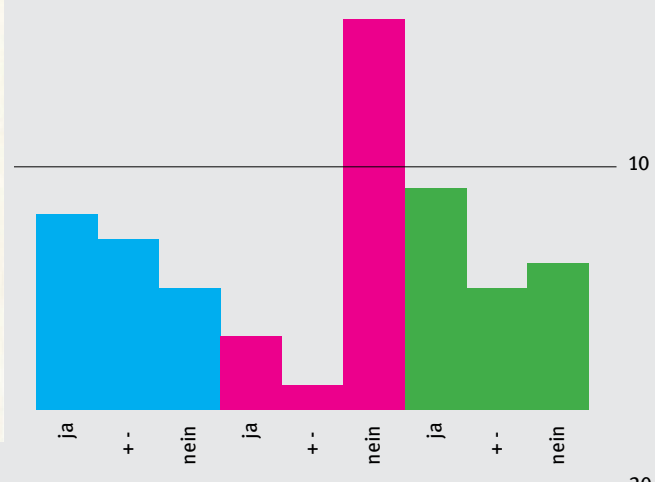

20
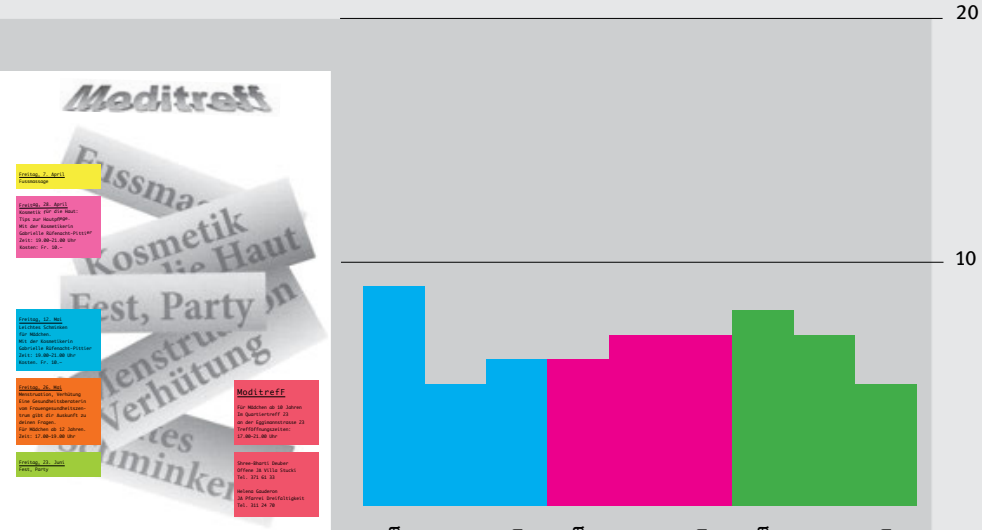



\section{moditreff}

frühling

Fussmassage

*

Kosmetik

für die Haut

(2)

(C)

Leichtes Schminken

für Mädchen



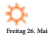

Menstruation,

Verhütung

Fest, Party
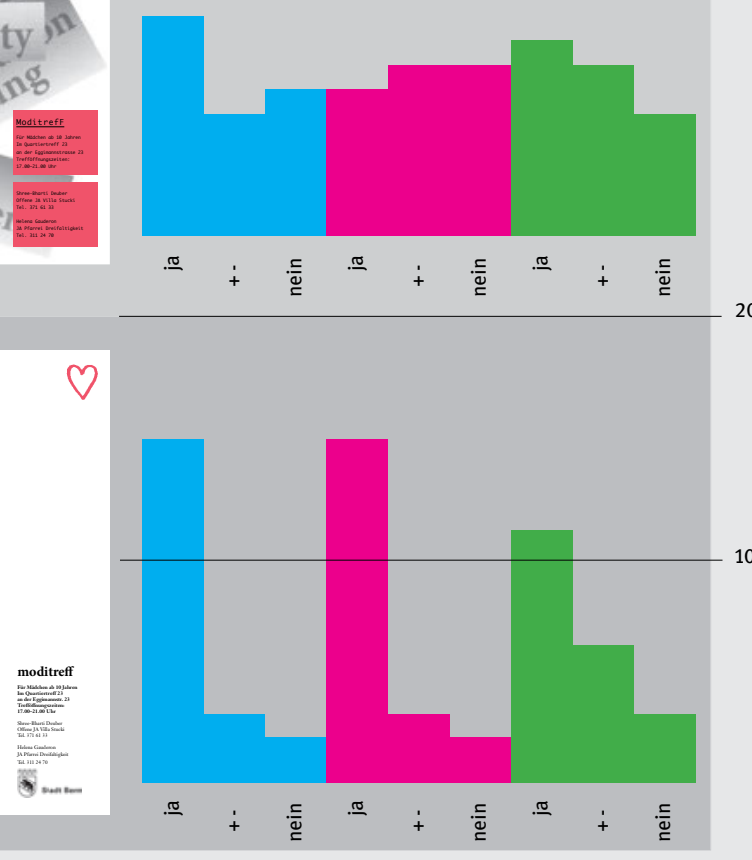
Bei der niedrigen Variante spielt die Referenz auf die Zielgruppe ebenfalls eine wichtige Rolle, um ihre Angemessenheit zu beurteilen. Oft unterscheiden die Befragten zwischen ihrer eigenen Wahrnehmung und jener, die sie bei den Mädchen vermuten, an die sich das Angebot richtet. Während sie die Gestaltungsweise der niedrigen Variante persönlich oft ablehnen, gehen sie doch davon aus, dass diese Variante zielgruppengerecht bzw. «für Mädchen ganz gut» sein könnte. Die Probanden sind sich nicht immer sicher, ob die Variante die Zielgruppe ansprechen würde oder nicht. «Ich kenne die Zielgruppe zu wenig» wird etwa zu bedenken gegeben oder man fragt sich, ob sich die Mädchen wohl von der verspielten Gestaltung angesprochen fühlten oder junge Frauen heute «an eine andere Designsprache gewöhnt» und ihre Erwartungen an die Gestaltung entsprechend «schon hoch entwickelt» seien. Die verspielte bis kindliche Gestaltung der Originalvariante könne besonders für die Gruppe der bereits «reiferen» Teenager-Mädchen unpassend sein, vermuten mehrere, vor allem weibliche Probanden. Bei der mittleren Variante wird gerade in die andere Richtung zu bedenken gegeben, dass die Art und Weise, wie sie gestaltet sei, eine «gewisse Reife» von der Betrachterin verlange und somit für die jüngeren Mädchen ungeeignet sein könne. Mit einer anspruchsvolleren Ausgestaltung zeige man jedoch auch, dass die jungen Frauen an diesem Ort ernst genommen würden. Wichtig ist bei der Einschätzung der Angemessenheit also auch die Rolle des Absenders, die Ethos-Ebene: Falls es gelte, den staatlichen Auftrag, das Angebot der öffentlichen Hand zu betonen und dem Ganzen einen seriösen Anstrich zu verleihen, wird die elaborierte Variante für angemessen gehalten, gehe es aber darum, das Angebot als informell, spontan und niederschwellig herauszustellen, erscheinen die mittlere oder die laiengestaltete, simple Variante passender.

Die Tatsache, dass die Veranstaltungsinformation des Mädchentreffs nicht im öffentlichen Raum wirksam sein muss, sondern «im Quartiertreff» ausgehängt oder ausgelegt wird, relativiert für die Befragten die Anforderungen sowohl an die Qualität als auch an die Plakativität der Gestaltung: «Es ist ja nicht ein Flyer, der überall hängt, also muss er nicht so gut sein». Schließlich sei beim gewählten Beispiel ein gewisser Zielkonflikt bereits in der anvisierten Zielgruppe und im beworbenen "Angebotsmix» angelegt, wie von mehreren Befragten angemerkt wurde: Die Spannweite innerhalb der Zielgruppe «Mädchen ab 10 Jahren` reiche von noch kindlichen Mädchen bis zu reiferen Teenagern, die sich für Erwachsenenthemen wie «Menstruation und Verhütung interessierten. Solche «ernsten» Themen erfordern aus Sicht der Probanden auf Ethos-Ebene tendenziell eine seriöser wirkende Gestaltung als Themen wie «leichtes Schminken` oder «ArmbänderKnüpfen〉. Visuell seien die verspielten Symbole und der bunte Farbmix auf den verschiedenen Varianten für eine jüngere Zielgruppe angemessen, für erwachsenere Mädchen und ernsthafte Themen jedoch weniger adäquat. Die «wilde» 
Gestaltung der mittleren Variante wiederum erscheint für Angebote wie ein Fest passend, nicht aber für die ernsteren Themen und den offiziellen Absender.

Wie die Mädchen der Zielgruppe tatsächlich reagieren, kann aufgrund der kleinen, durchmischten Testgruppe leider nicht überprüft werden. ${ }^{4}$ Allerdings zeigt sich beim einzigen Teenager-Mädchen, das im Rahmen der Wirkungsstudie befragt wurde, dass es teils gänzlich außerhalb der Professionalitäts- und Angemessenheitskategorien der erwachsenen Testpersonen denkt. Anders als die meisten dies beurteilen, hält die Fünfzehnjährige beispielsweise die «Schreibart» der niedrigen Variante für «passend und leicht verständlich», die Gesamterscheinung findet sie zwar «etwas blass», aber «recht gut und übersichtlich». Sie hält die Originalvariante insgesamt für angemessen und «recht professionell» gestaltet, allenfalls «könnte es noch etwas farbiger sein». Obschon bereits zu den älteren Mädchen der Zielgruppe gehörig, gefällt der jungen Frau bei allen Varianten vor allem ihre Farbigkeit, und bei der niedrigen Variante fallen ihr weder Mängel in der technischen Ausarbeitung und Erkennbarkeit noch die unprofessionelle Machart auf. Aufgrund dieses einen Beispiels lässt sich noch keine generelle Aussage über die Wirkung der Varianten auf ihre Zielgruppe machen. Zumindest lässt sich jedoch vermuten, dass sich die Zielgruppe nicht unbedingt dadurch erreichen lässt, dass Elaborationsstandards auf professionellem Niveau umgesetzt werden. Ebenfalls kann angenommen werden, dass gestalterische Imperfektionen und Mängel nicht unbedingt $\mathrm{zu}$ einem schlechteren Resultat führen müssen.

Bei den erwachsenen Probanden fließt der wahrgenommene Professionalitätsgrad, verbunden mit der technisch-materiellen Ausarbeitung, zwar reflektierter in die Einschätzung der Angemessenheit ein - jedoch auch hier nicht immer nur im Sinne von «je elaborierter, desto angemessener». Von einigen wird die offensichtlich niedrigere Professionalitätsstufe der weniger elaborierten Varianten als ausreichend oder sogar als positives Merkmal gesehen. Einige halten bereits die Variante «mittel〉 für «zu professionell» zur Propagierung eines Mädchentreffs. Oder es wird lobend dazu vermerkt: «Ein Profi hätte es nicht besser machen können» - und falls tatsächlich ein professioneller Gestalter am Werk gewesen sei, so habe er «sehr gut verstanden, was den Mädchen gefällt». In eine ähnliche Stoßrichtung geht auch die Bemerkung, dass der Flyer für den «Moditreff» «auf keinen Fall Hochglanz» sein dürfe und der «Billigdruck» in diesem

4 Die Klärung dieser Frage wäre Gegenstand einer weiteren Studie. Da für die hier vorliegende Untersuchung alle Personen zu allen Artefakten befragt wurden und insgesamt nur zwanzig Personen zur Verfügung standen, d.h. verschiedene Altersgruppen und auch männliche Personen berücksichtigt werden mussten, konnte lediglich ein Mädchen im Alter der Zielgruppe befragt werden. 
Kontext absolut angemessen sei. Selbst wenn die niedrige Variante nicht gut gestaltet sei, so zeige sie durch ihre wenig elaborierte Erscheinung doch gerade, dass nicht viel Geld für die Kommunikation ausgegeben worden sei, was in diesem Kontext positiv zu deuten sei: «Man soll das Geld für die Inhalte brauchen». Gleichzeitig mindern oder verstärken der aufgewendete «Effort» bzw. die Sorgfalt, welche sich für die Betrachter in der Erscheinung der Gestaltungsvarianten widerspiegeln, ihre Einschätzung der Angemessenheit - und zwar selbst im Rahmen der Laiengestaltung. Viele bemängeln bei der Originalvariante, hier habe sich der Gestalter oder die Gestalterin «zu wenig Mühe» gegeben, andere betonen beim Artefakt aber gerade in positiver Weise, man habe sich beim Gestalten offensichtlich «Mühe gegeben».

Laiengestaltung - sofern mit ausreichender Sorgfalt ausgeführt - und «lowtech>-Produktion sind aus Sicht der Befragten folglich ein gangbarer Weg zu einer adäquaten Gestaltungslösung im Bereich der Jugend- und Gemeinwesenarbeit. Damit erweist sich nochmals, dass der Grad der Professionalität und die wahrgenommene Angemessenheit nicht immer übereinstimmen müssen. Gestaltung im Bereich der Gemeinwesenarbeit kann sich einerseits als sprofessionell, aber unpassend s erweisen. Nämlich dann, wenn sie im gegebenen Kontext zu professionell, zu hochwertig, zu anspruchsvoll - also zu elaboriert - erscheint. Andererseits kann sie zwar «schlecht gestaltet, aber in Ordnung〉 sein, d.h. zwar simpel und laienhaft, selbstgebastelt oder unfachmännisch ausgeführt sein, aber doch ihren Zweck erfüllen und dem Zielpublikum, Thema und Absender entsprechen.

\subsubsection{Disparate Beurteilungen: Was spricht die Mädchen an? Die Varianten im Vergleich}

Für sich genommen wird die niedrige Originalvariante des «Moditreff -Aushangs meistens als unprofessionell und die hohe Variante meistens als professionell betrachtet, während die Einschätzung der mittleren Variante dazwischen liegt. Diese Betrachtung spiegelt sich deutlich in der relativen Einstufung der drei Varianten (vgl. Grafik 31 für eine Übersicht): Bis auf zwei Ausnahmen halten alle Testpersonen die Variante 〈hoch〉 für die professionellste der drei Varianten (einmal zusammen mit der mittleren) und für fast ebenso viele Personen ist die niedrige Originalvariante auch die unprofessionellste der drei Elaborationsvarianten (zweimal zusammen mit der mittleren). Die mittlere Variante landet am häufigsten in der Mitte oder wird gleichauf mit einer anderen Variante eingestuft. Nur gerade zwei (bzw. drei) Personen halten die mittlere für die professionellste Variante und niemand stellt bezüglich der Professionalität das Original an die Spitze. Die Reihenfolge «hoch - mittel - niedrig〉 ist mit zwölf (bzw. fünfzehn) 
Nennungen dominant, was aufgrund der verwendeten Elaborationsmerkmale auch so zu erwarten war.

Betrachtet man dagegen die graduelle Einstufung nach der Angemessenheit, ergibt sich ein verändertes und stärker zerstückeltes Bild (vgl. ebenfalls Grafik 31). Hier wird die elaborierte Variante nur noch zehnmal (bzw. elfmal) an die erste Stelle gesetzt und erhalten die mittlere sowie nun auch die niedrige Variante je viermal (bzw. fünfmal)den ersten Platz. Alle drei Varianten landen zudem fast gleich oft in der Mitte, wobei dies bei der mittleren Variante immer noch knapp am häufigsten der Fall ist. Die Variante ‘hoch` findet sich am seltensten, nämlich nur zweimal (bzw. viermal), an letzter Position wieder. Die Reihenfolge shoch mittel - niedrig> kommt mit einem Viertel zwar noch am häufigsten vor, dicht gefolgt von je drei Nennungen der Anordnung shoch - niedrig - mittel und «niedrig - hoch - mittel`. Darüber hinaus werden auch alle restlichen Möglichkeiten gewählt: «niedrig - mittel - hoch〉, «mittel - hoch - niedrig〉 und «mittel - niedrig - hoch». Das disparate Gesamtbild zeigt, dass in Sachen Angemessenheit weniger Konsens zwischen den Befragten herrscht als bei der Einschätzung der Professionalität. Die vielen verschiedenen Bewertungsmuster lassen sich auch auf Unsicherheit einzelner Versuchspersonen hinsichtlich der Passung der verschiedenen Varianten zur Zielgruppe und zum beworbenen Angebot zurückführen. Bei der Einstufung der Angemessenheit werden oft Relativierungen und «Mischrechnungen» gemacht. So wird beispielsweise die mittlere Variante als «cool, aber nicht angemessen» wahrgenommen und das Original als «angemessen, aber zu einfach» beurteilt, so dass am Ende auf der Angemessenheitsskala beide gleich bewertet werden.

Die Tatsache, dass sich bei der Angemessenheit nicht dasselbe Bild wie bei der Professionalität ergibt, bestätigt die Annahme, dass der Professionalitätsgrad - sowie mit ihm verbundene Elaborationsmerkmale der technischen Ausarbeitung, Qualität, Konzepthaftigkeit, Originalität etc. - nicht für alle Befragten zwingend hoch sein muss, damit sie eine Variante für angemessen halten. Unter Berücksichtigung des Kontexts kann eine Variante trotz - oder gerade wegen - des niedrigen Elaborationsgrads als passend beurteilt werden. Gleichwohl scheint ein bedeutender Teil der Testpersonen bei den Gestaltungsvarianten zum Mädchentreff die Kriterien der Professionalität und Angemessenheit gleich oder analog anzuwenden, d.h. für sie mindert oder vergrößert sich der Grad der Angemessenheit zusammen mit der wahrgenommenen Professionalität. Dadurch ergibt sich auf beiden Ebenen exakt dieselbe Reihenfolge - was tatsächlich bei knapp einem Drittel der Personen der Fall ist (diese Korrelation ist in Grafik 31 nicht abgebildet). Auch zeigt sich bei Personen mit niedrigem Bildungsstand häufiger eine Korrespondenz in der gewählten Reihenfolge als bei den Personen, die mindestens einen Fachhochschulabschluss haben. Dieser Umstand korreliert, 





wie schon bei den Designvarianten zum Wahlprospekt, mit der Tatsache, dass die Probanden mit niedrigerem Bildungsstand fast ausnahmslos die elaborierte Variante auch für die angemessenste halten. Jene, welche Professionalität und Angemessenheit unterschiedlich bewerten, präferieren oft die niedrige Variante bzw. das Original. Gleichzeitig sind es ausschließlich die Personen mit höherer Bildung, welche die mittlere Variante für die angemessenste halten. Insgesamt schneidet die mittlere Variante bei den Personen ab Fachhochschule sogar am besten ab, wenn auch nur knapp. Die hohe und niedrige Variante werden bei diesen etwas weniger oft, aber beide von gleich vielen Personen als angemessenste Variante genannt.

Betrachtet man den Wohnort der Befragten, so ergibt sich bei der Stadtbevölkerung eine heterogenere Verteilung der Angemessenheit auf alle drei Varianten als außerhalb der Stadt. Doch insgesamt überwiegen in Stadt, Land und Agglomeration die Stimmen für die hohe Variante. Anders als man angesichts der altersspezifischen Zielgruppe des Aushangs vermuten könnte, gibt das Alter der Probanden keinerlei Hinweis darauf, wie sie die Angemessenheit der Varianten einschätzen. In allen Altersgruppen kommen Präferenzen für die niedrige, die mittlere und die hohe Variante vor und es lässt sich keine auffällige Verteilung erkennen, die spezifisch für ein Lebensalter wäre. Leichte geschlechterspezifische Vorlieben lassen sich hingegen finden. So setzen die befragten Frauen alle drei Varianten fast gleich oft auf die höchste Stufe der Angemessenheit (mit leichtem Vorsprung der Variante 〈hoch〉), während sich bei den Männern eine ausgeprägte Vorliebe für die elaborierte Variante zeigt. Der Versuch, mit den verspielten, handgemachten Elementen der mittleren Variante ein weibliches Publikum anzusprechen, scheint somit zumindest bei einigen Frauen im Testpublikum erfolgreich gewesen $\mathrm{zu}$ sein. Allerdings bewerten insgesamt immer noch mehr Frauen die mittlere Variante als die am wenigsten angemessene Variante. ${ }^{5}$

5 Da die Testpersonen das Angebot eines Mädchentreffs ausnahmslos für sehr sinnvoll oder zumindest für sinnvoll halten und alle eine Tochter im Alter der Zielgruppe beim Treff mitmachen lassen würden, können aus dieser Information keine Erkenntnisse abgeleitet werden. 


\subsection{Resultate Designvarianten Flugblatt Freiwillige Feuerwehr}

\subsubsection{Wirkungen: Lokalkolorit, Action, Esprit}

Variante «niedrig〉 (Original) - nüchtern und zweckmäßig: Der Originalflyer der Freiwilligen Feuerwehr (Abb. 80) erscheint den Probanden zweckmäßig und typisch für einen Absender aus dem Bereich der freiwilligen Gemeinde- oder Quartierarbeit: «Genau so muss man es machen», «einfach so, wie man es kennt». Die Variante «niedrig» erhält einerseits positive Beurteilungen von «gut gemacht», «Ich mag diese Bildsprache» bis «sehr gut» und sie wird als «überschaubar», «klar», «handlich», «simpel» sowie «ansprechend», «freundlich» beschrieben. Andererseits wird ihre konventionelle und etwas krude Gestaltungsweise auch negativ beurteilt, von «langweilig», «öde» bis zu: «Das kann man nicht machen». Als typisch für diese Art der Gestaltung gilt vielen die Tatsache, dass auf dem eher kleinen Format A5 sehr viele und daher entsprechend kleinformatige Bilder eingesetzt wurden: «man will alles zeigen», «man wollte alles reinpacken». Durch die zahlreichen Bilder sehe man zwar auch viel vom Feuerwehralltag, müsse aber näher hinschauen, um etwas zu erkennen. Einige Probanden fänden es besser, statt der vielen kleinen Fotos nur ein Bild in «anständiger Größe» zu sehen. Auffallend oft kritisiert wird die Hinterlegung von Fotos hinter den Text. Das Hintergrundbild sei «zu viel des Guten», das Ganze wirke dadurch «unruhig», es könne einem «fast schlecht werden» beim Betrachten. Zudem lasse das Foto den darüber gelegten Text «unleserlich» werden, weder das eine noch das andere werde richtig sichtbar. Das Hinterlegen eines abgeschwächten Bilds wird auch als veraltete Technik beurteilt, die «bestenfalls aus den 1990er Jahren» stamme bzw. die man «früher» angewendet habe. Eine Person empfindet den hinterlegten Hintergrund aber auch als «schön». Irritierend und unpassend wirkt auf einige der Befragten das Mädchen auf der Leiter im Hintergrund. Andere ordnen das Bild in den Kontext eines Tags der offenen Tür ein und attestieren dem Bild eine «familiäre» Wirkung. Positiv bemerkt wird die Markierung wichtiger Wörter in der Farbe Rot, welche einen passenden Bezug zur Feuerwehr schaffe. Der «saubere» Blocksatz der Informationen auf der Rückseite gefällt einigen sogar besser als der professionelle Flattersatz bei der mittleren Variante.

Allzu sichtbare und vermeidbare Fehler in der technischen Ausarbeitung stoßen bei den Befragten auf Kritik: Der Flyer wirke «unruhig» und «wild», da eine Hierarchisierung der Elemente und eine ausreichende Betonung der wichtigsten Aussagen fehle. Die Fotos wirkten «unprofessionell» und «zu dunkel». Bemängelt wird bei der Originalvariante überdies, das Logo sei zu groß dargestellt und schlecht gemacht, ja dessen Qualität sei «himmeltraurig», "grauenhaft», es sehe aus, als wäre es «von einer Wand abfotografiert» worden. Durch 
Variante «hoch〉 betrachten, beurteilen diese deutlich besser also jene, die vorher eine der bebilderten Varianten gesehen haben. Von den Erstbetrachtenden wird die hohe Variante als «ok dargestellt», «klar», «lebendig», «ansprechend», «auffällig», «sympathisch», «modern», «zeitgemäß», «urban», «simpel und einfach» und als inhaltlich sinnvoll betrachtet: «Die brauchen Leute». Der orange Flyer weckt auch Interesse: «Es hat mich gereizt zu schauen, wie es weiter geht». Der «Fusion von Schrift und Farbe» wird eine die Aufmerksamkeit stark anziehende Wirkung attestiert. Dabei seien die Farben «gut gewählt», schüfen einen Bezug zum «Feuer» und entfalteten eine «Warnfunktion»; die Streifen sähen aus «wie Absperrbänder» und passten zum «aktiven Feuerwehrdienst». Die Optik der Farbstreifen wirkt auf manche Befragte auch «irritierend», «fast psychedelisch». Das Papier der Variante 〈hoch〉 wird als «fein», «nicht zu dünn» und «schön» empfunden. Auch ohne zuerst eine bebilderte Variante gesehen $\mathrm{zu}$ haben, fällt den Probanden auf, dass hier «nur typografisch» gearbeitet werde, d.h. «ohne Logo oder Symbolik», was auch bedeute: «Man muss es lesen». Auch unter jenen, welche die Variante 〈hoch» zuerst beurteilten, halten einige diese Variante lediglich für «nicht schlecht», «relativ adäquat», «neutral» oder gar für «langweilig» und «zu brav».

Jene Versuchspersonen, welche zuerst eine oder gar zwei bebilderte Varianten gesehen haben, reagieren anders. Kritikpunkt Nummer eins ist hier: «Die Bilder fehlen», «Da muss ein Bild rein» oder «Die Fotos der Feuerwehr in Aktion fehlen». Es brauche ein Bild, um die Emotionen anzuregen, z.B. «Feuerwehrleute, die in Gefahr helfen, die ein Kätzchen retten». Worte allein seien zu wenig: «Der Text interessiert nicht - Bilder machen mehr Lust». Bei jenem Drittel, der zuerst mit der orangen Variante konfrontiert wurde, wird das Fehlen von Abbildungen dagegen kein einziges Mal als Mangel kritisiert. Bei den übrigen zwei Dritteln wird die Variante manchmal sogar sofort abgelehnt: «Geht gar nicht», «Das ist gar nicht mein Geschmack». Mehrere Personen sehen in der elaborierten Variante einen «normalen Werbeflyer», wie man ihn täglich im Briefkasten finde und der «sofort im Abfall» bzw. «im Altpapier» landen würde. Anderen gefällt der Flyer zwar persönlich - er wirke auf sie «sehr schön», «andersartig», «weniger bieder», «interessant», «strukturiert», er ziehe durch den «starken Kontrast» die ganze Aufmerksamkeit auf sich -, taxieren ihn aber trotzdem als unangemessen. Sie halten ihn aufgrund des fehlenden Bilds und des Verzichts auf den Bild und Text verbindenden Slogan «Mit der Feuerwehr hoch hinaus` für ungeeignet. Andere Gründe für die Ablehnung sind die «Bleiwüste» oder die «kühle» und «ernste», «grelle» und «durchdringende» Wirkung dieser Variante. Der Flyer passe nicht beabsichtigten Zweck und werde dem Absender Freiwillige Feuerwehr nicht gerecht. Einigen gefallen schlicht die Farben nicht oder sie halten die Gestaltung für $\mathrm{zu}$ wenig ansprechend. Auch Imperfektionen in der Detailausgestaltung werden kritisiert. Es wird etwa gewünscht, dass der Text vorne «zentriert» 


\section{Mit der FEUERWEHR hoch hinaus!}

Wir suchen DICH für den aktiven Feuerwehrdienst!
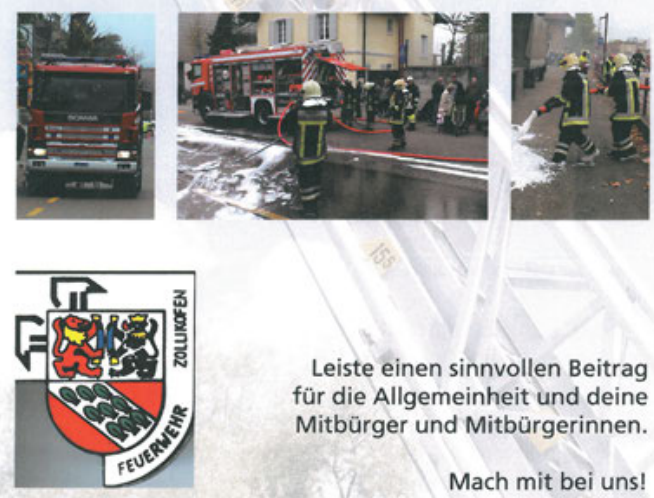

Leiste einen sinnvollen Beitrag für die Allgemeinheit und deine Mitbürger und Mitbürgerinnen.

Mach mit bei uns!

Wer steckt hinter der Miliz-feuerwehr Zollikofen?

Wir sind etwa 80 Feuerwehrmanner und -frauen, welche in der Gemeinde
zollikofen freiwillig feuenwehrdienst leisten; Eingeteilt in drei 20 ge (Pikett: Verkehrs- und Unterstotrungszug).

Wirretten Menschen und Tiere, Ioxchen Brande, pumpen uberschwemm Keller sus, beseitigen Olspuren auf der Strasse und helfen oberall dort, wo Menschen in Not geraten.

( wir deingend feuerwehr-Nactwuchs und suchen desha/b DiCH!

\section{Wir bieten DIR}

eine vielfatige Ausbildung, moderne Ausrostung und Fahrzeuge, Kameradschatt und das Arbeiten im Team. Zudem wird dir die Feverwerden finanziell entschadige.

\section{Unsere Erwartungen an DiCH}

Wohnsitz in der Gemeinde Zolkikofen, zwischen 19 und 40 Jahren, die Bereitschatt zum Besuch von 7 oder mehr Ubungen pro lahe sowie Erreichbarkeit und Mobilitat.

\section{Maben wir dein interewe geweckt? Dann melde didr doch unverbindlich}

Haben wir dein interesse geweckt? Dann melde diphdoth umbinalih

Feuerwehrsekretariat Zollikofen Feuerwehrkommandant

do Gemeindeverwaltung Hptm Bruno Küenzi

Wahlackerstrasse 25 Reichenbachistrasse 54

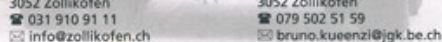

Abb. 80: Designvariante niedrig, Freiwillige Feuerwehr Zollikofen (Original) 
das Wappen erhalte der Flyer aber «Lokalkolorit», was im Kontext der lokalen Feuerwehr passe. Auf der Rückseite der Variante «niedrig〉 kritisieren fast alle Personen die Hinterlegung eines Bildes als «überflüssig» und fühlen sich davon im Lesefluss gestört, zumal das Löschfahrzeug in Frontalansicht bereits vorne gezeigt werde. Den Löschwagen zu inszenieren, halten einige für sinnvoll, da dieser «der Stolz der Männer» bei der Feuerwehr sei - der Rat, man hätte auch bei der mittleren Variante lieber den Einsatzwagen in den Mittelpunkt gestellt, stammt allerdings von einer Frau.

Variante «mittel〉 - die attraktivere Variante des Prototyps: Die Gestaltungsvariante 〈mittel〉 (Abb. 81), bei der versucht wurde, die vorhandenen Mittel des Originals professioneller einzusetzen, erntet einhellig die besten Beurteilungen. Die mittlere Flyervariante erscheint den Befragten «gut gemacht», «recht professionell», «attraktiv», «cool», «klar» und «passend für das, was man will», oder ihr wird immerhin noch mit dem Urteil «ok, alles da» oder «warum nicht?» begegnet. In der Gesamterscheinung wirkt die Variante 〈mittel〉 auf viele ähnlich wie das Original. Sie sei immer noch «ein typischer Feuerwehrflyer», der den Absender weitestgehend so repräsentiere, «wie man ihn kennt», «wie man es erwarten würde» und auf dem typischerweise «ein großes Bild, einfache Schrift, eine «Catchphrase» und das Logo unten in der Ecke» zu sehen seien. Auch das kompakte Format des Flyers entspricht der gängigen Vorstellung. Diese Art der Gestaltung «verfehlt nicht ihr Ziel», sie «erfüllt ihren Zweck».

Der gegenüber dem Originalflyer geringfügig verbesserte Elaborationsgrad wird vom Testpublikum sehr genau bemerkt und im Normalfall auch positiv gewertet. Im Unterschied zur niedrigen Variante lasse das «großflächige» Bild nicht nur sofort ersichtlich werden, worum es gehe, sondern es diene auch als «Motivationsspritze» für Interessierte: «Das zieht», «Das wirkt stark». Das gewählte Motiv wird mehrheitlich als «gut», «professionell», «passend», «spannend», «emotional», «cool», «aktivierend» wahrgenommen, weil es die «Action» betone, die Höhe sichtbar mache, die «Perspektive von oben» zeige und mit der Leiter, dem Rauch, dem Feuerwehrauto und der Bedienzentrale sowohl die technischen Details zeige als auch den «Schwindel» und «Kitzel» erlebbar mache: «Da geht was ab», «Man ist mittendrin», «Yeah! Ich will auch auf den Knopf drücken», «Cool, ich rufe gleich an!» Umgekehrt wird moniert, das Bild wirke «zu gefährlich» und es vermittle, dass hier Leute gesucht würden, welche sich der Gefahr aussetzen wollen. Damit sei eine Möglichkeit verpasst worden, die Feuerwehr «sympathischer» darzustellen oder «mehr Respekt herauszuholen». Das Bild mit dem Rauch wirke «negativ», «nicht ansprechend», auch weil man das Gesicht der Feuerwehrmanns nicht sehe. 


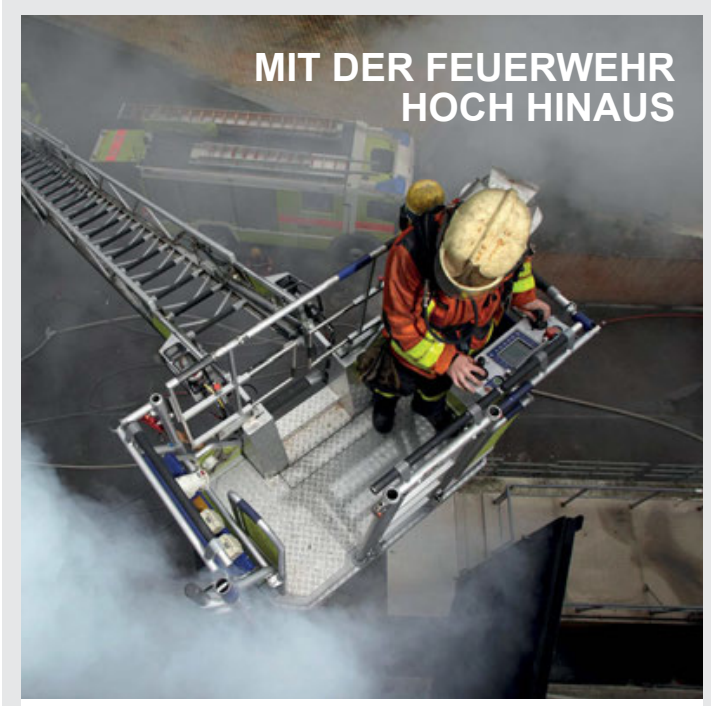

\section{Wir suchen DICH für den aktiven Feuerwehrdienst!}

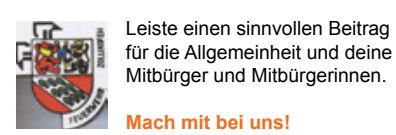

\section{Wer steckt hinter der Miliz-Feuerwehr Zollikofen?}

Wir sind etwa 80 Feuerwehrmänner und -frauen, welche in der Gemeinde ingeteilt in drei Züge (Pikett-, Verkehrs- und Unterstützungszug).

Wir retten Menschen und Tiere, löschen Brände, pumpen überschwemmte Keller aus, beseitigen Ölspuren auf der Strasse und helfen überall dort,

wo Menschen in Not geraten.

Damit wir unsere Aufgaben weiterhin optimal erfüllen können, benötigen wir dringend Feuerwehr-Nachwuchs und suchen deshalb DICH!

Wir bieten DIR

eine vielfälltige Ausbildung, moderne Ausrüstung und Fahrzeuge, Kameradschaft und das Arbeiten im Team. Zudem wird dir die Feuerwehrersatzabgabe erlassen und deine Dienstleistungen in der Feuerwehr werden finanziell entschädigt.

Unsere Erwartungen an DICH

Wohnsitz in der Gemeinde Zollikofen, zwischen 19 und 40 Jahren, die Bereitschaft zum Besuch von 7 oder mehr Ubungen pro Jahr (vorwiegen am Montagabend), die Bereitschaft im Alarmfall auszurücken sowie Erreichbarkeit und Mobilität.

\section{Haben wir dein Interesse geweckt?}

Dann melde dich doch unverbindlich bei der Feuerwehr:

$\begin{array}{ll}\text { Feuerwehrsekretariat Zollikofen } & \text { Feuerwehrkommandant } \\ \text { c/o Gemeindeverwaltung } & \text { Hptm Bruno Küenzi } \\ \text { Wahlackerstrasse 25 } & \text { Reichenbachstrasse 54 } \\ \text { 3052 Zollikofen } & 3052 \text { Zollikofen } \\ \text { a 031 910 91 11 } & \mathbf{2 0 7 9} 5025159 \\ \square \text { info@zollikofen.ch } & \square \text { bruno.kueenzi@jgk.be.ch }\end{array}$

Abb. 81: Designvariante mittel, Freiwillige Feuerwehr Zollikofen 
Positiv vermerkt wird, dass der Text die Leute «direkt» und «persönlich» anspreche, was durch das groß geschriebene und rot gesetzte Wort «dich» noch betont werde. Die Schriftgestaltung sei insgesamt «sauber», «klar» und «leserlich». Die roten und schwarzen Farbakzente werden mit der Feuerwehr assoziiert, was als passend wahrgenommen wird. Auf der Rückseite ist für einige zwar etwas viel Text platziert, dieser sei aber «schön aufgebaut» und mit Absätzen und Überschriften unterteilt. Jemand sähe den Text lieber in Blocksatz «anstatt linksbündig» in Flattersatz. Im Gegensatz zum Originalflyer, wo dies aufgrund der vielen visuellen Reize und mangelnden Hierarchisierung untergegangen $\mathrm{zu}$ sein scheint, sticht bei der mittleren Variante der Slogan «Mit der Feuerwehr hoch hinaus` ins Auge und wird positiv bewertet: «Motto und Foto passen», die Komposition sei «überlegt» und «witzig» bzw. ergebe einen «Bildwitz». Das Logo ist einigen Probanden «zu klein» dargestellt, andere erachten es für «nicht schön» gestaltet, was hier aber weniger auffällt als bei der Originalvariante.

Im Vergleich mit der niedrigen Variante befinden viele das Bild hier für besser, die Aussage für klarer und die Gestaltung insgesamt für professioneller. Die Reduktion auf ein großes Bild wirke pointierter, das Wortspiel komme besser zur Geltung, der Text sei «am richtigen Platz» und auf der Rückseite sei die Information ohne das hinterlegte Bild angenehmer und leichter zu lesen. Nicht alle ziehen aber die mittlere Variante der niedrigen vor: Die Variante «mittel〉 sei professioneller gestaltet, wirke jedoch durch das professionelle Bild und die saubere technische Ausgestaltung «weniger authentisch» und «weniger charmant». Jemand findet auch, die Gestaltung der mittleren Variante komme daher wie ein «Spendenaufruf», was bei der niedrigen nicht der Fall sei. Im Vergleich mit der elaborierten Variante entspreche die mittlere Variante mehr den gängigen Vorstellungen der Freiwilligen Feuerwehr. Sie erscheint den Befragten «normaler», «seriöser», «weniger übertrieben» - aber auch «weniger spannend», «weniger auffallend», «weniger spektakulär», «weniger jung» - als die Variante 〈hoch〉.

Variante 〈hoch〉 - etwas ganz anderes: Die elaborierteste der drei Varianten in den Farben Orange und Schwarz (Abb. 82) wird von den Befragten hoch kontrovers beurteilt: Man liebt sie oder man hasst sie. Sie ist auch jene Variante, die sich in der Gestaltung am klarsten von den anderen Varianten abhebt. Aufgrund der konsequenten Umsetzung der formulierten Gestaltungsidee verzichtet diese Variante gänzlich auf Bebilderung und setzt ganz auf die Wirkung von Schrift, Form und Farbe. Die verhältnismäßig große Eigenständigkeit dieser Lösung spiegelt sich in den Urteilen der Befragten. In positiver wie negativer Hinsicht wird vom orangen Flugblatt gesagt: «Das ist etwas ganz anderes». Deshalb spielt es in stärkerem Maß als bei den zuvor besprochenen Dreierserien eine Rolle, welche Variante die Probanden zuerst zu Gesicht bekommen. Jene Personen, die zuerst die 


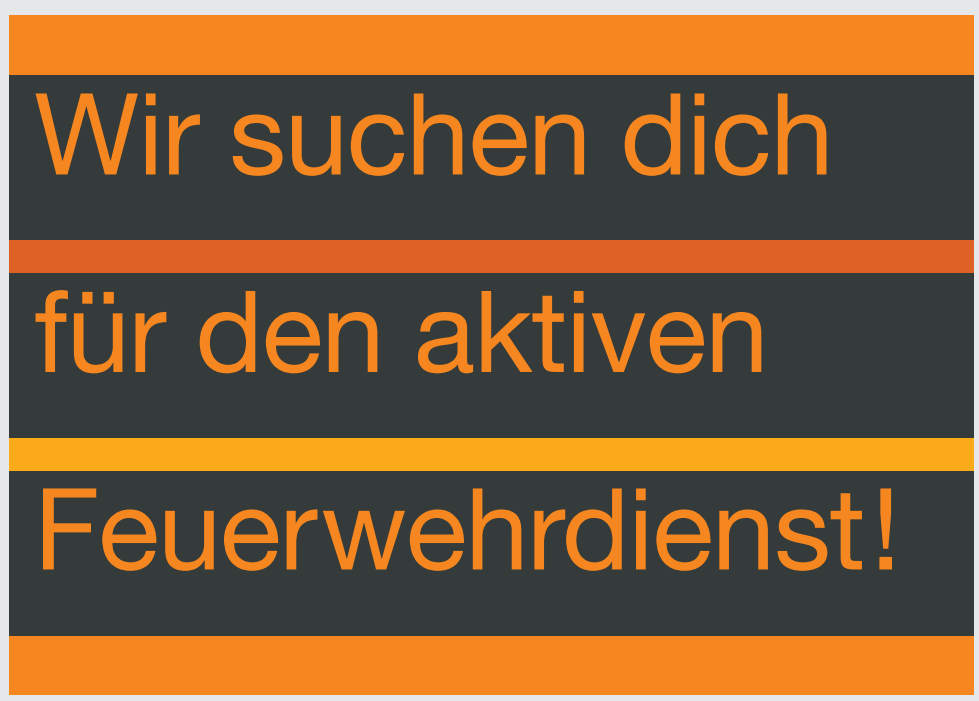

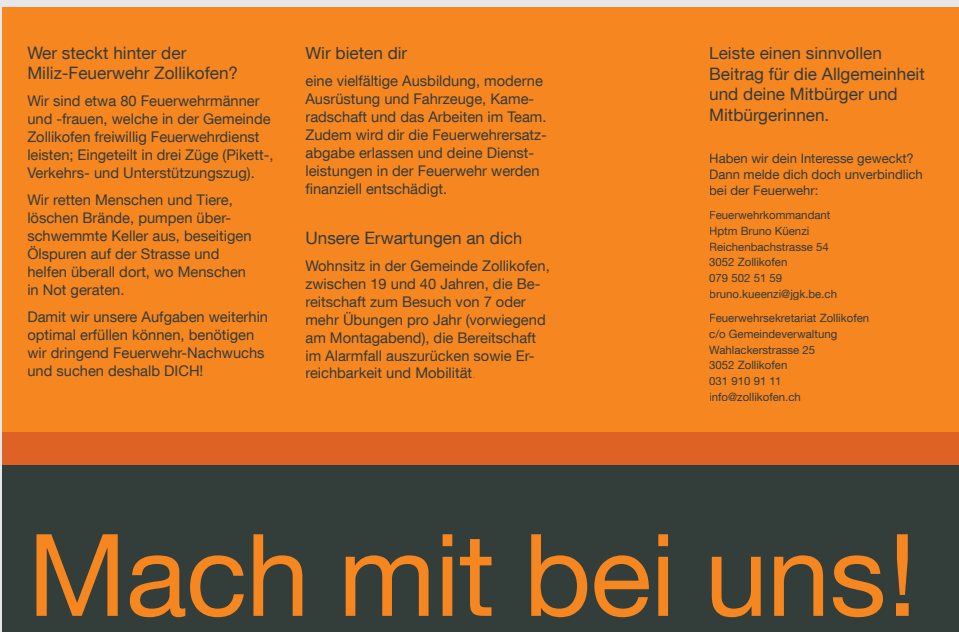

Abb. 82: Designvariante hoch, Freiwillige Feuerwehr Zollikofen 
werden solle, so dass er auf den schwarzen Balken «gleich ausgerichtet» wäre. Die Lesbarkeit der Informationen auf der Rückseite sei aufgrund des Kontrasts und der kleinen Schrift schlecht.

Trotz der Kritik gibt es auch bei der Gruppe der zuerst mit der bebilderten Variante Konfrontierten positive Stimmen: «Warum nicht einmal etwas anderes?». Die Variante umgehe das «Vorurteil vom Held auf der Hebebühne im Rauch» in erfrischender Weise. Für einen Verwendungszweck im öffentlichen Raum wird dem elaborierten Flyer aufgrund seiner leuchtenden Farben und seiner Prägnanz attestiert, dass man «eher darauf schauen würde» als bei den anderen Varianten. Einige erachten die Variante als «gut und klar gestaltet», das Orange als passend, «die Aufforderung zum Mitmachen» stehe hier in positiver Weise im Zentrum. Doch nur gerade vier der insgesamt zwölf Personen, die zuerst mit einer bebilderten Version konfrontiert waren, erachten die elaborierteste Variante vorbehaltlos als angemessen. Jene Personen, die als erstes den orangen Flyer gesehen hatten, halten diese Variante dagegen für absolut angemessen (bzw. einmal für knapp angemessen). Damit wird sichtbar, dass die Erwartungen an die Gestaltung mit Sehgewohnheiten verknüpft sind bzw. wie stark unser Maßstab beeinflusst wird durch das, was wir in einem ähnlichen Kontext schon gesehen haben.

\subsubsection{Erkennbarkeit: Klarheit auf den ersten Blick - oder attraktives Schriftbild}

Die Erkennbarkeit bewegt sich aus Sicht der Befragten bei allen drei Designvarianten der Freiwilligen Feuerwehr in einem guten bis sehr guten Rahmen. Dennoch schneiden die bebilderten Varianten deutlich besser ab. Bei den Varianten 〈mittel〉 und «niedrig〉 ist für nahezu alle Testpersonen die Sache «auf den ersten Blick» klar (vgl. Grafik 32 für eine Übersicht der Einschätzungen). Bei der Originalvariante wird die Erkennbarkeit geringfügig schlechter beurteilt: Wegen der übermäßig vielen Bilder und Ebenen müsse man «zweimal hinschauen», um die Botschaft zu verstehen. Umgekehrt lasse der leicht handgestrickte Charakter der niedrigen Variante die Einordnung des Angebots in den Bereich der Freiwilligenarbeit am einfachsten zu. Die elaborierte Variante führt auch hier zu einem kontroversen Resultat: Für fast zwei Drittel der Befragten wird der Zusammenhang sehr rasch klar, für einen Viertel jedoch überhaupt nicht - und in der Mitte stufen den Flyer nur gerade zwei Personen ein.

Bei der Evaluation der Erkennbarkeit der Variante «hoch» spielt es erneut eine Rolle, ob die Personen den rein typografischen Flyer als erstes vor sich haben oder ob sie davor bereits ein bebildertes Beispiel gesehen haben. Beginnen sie mit der Variante 〈hoch〉, so lautet die Antwort eher, bei dieser werde «auf den ersten Blick sonnenklar, worum es geht», die «Message» sei klar, «der eine Satz 
sagt alles» oder es werde «mit wenigen Worten klar, was Sache ist». In dieser Gruppe wird kaum eingewendet, das Design habe mit der Feuerwehr «nicht viel zu tun». Jene, die zuerst eine oder beide Flugblattvarianten mit Bildern aus dem Feuerwehralltag betrachtet haben, lehnen die rein typografische Variante dagegen öfter als unzugänglich ab: «Man sieht nicht, was es ist», «Das hat mit der Sache nichts zu tun», «Das wird nicht gelesen». Verschiedentlich wird die Erscheinung der orangen Variante denn auch mit typfremden Gestaltungsbereichen wie «normaler Werbung», «Geldsammelaktionen» oder «Partyflyer» in Verbindung gebracht. Die Gestaltung wecke Assoziationen mit anderen Kontexten oder erinnere «an etwas anderes», weshalb auch nicht klar werde, dass es um einen «guten Zweck» gehe: «Ich käme nie auf die Idee, dass es um ein Freiwilligenangebot wie die Feuerwehr geht». Jemand findet hingegen, man müsse zwar zuerst den Satz lesen, um zu verstehen, worum es gehe, aber dies sei bei dieser Variante ja gerade «der Clou». Der Flyer lasse sich gerade aufgrund seiner auffälligen, besonderen Erscheinung und dem prominent platzierten Aufruf rasch erfassen. Die polarisierende Wirkung lässt sich somit zumindest teilweise auf die Andersartigkeit des Flugblatts zurückführen: Das «Erkennen als` wird erschwert, weil die Gestaltung nicht genretypisch ist und nicht den Sehgewohnheiten der Befragten entspricht - doch umgekehrt aktivieren gerade diese Abweichungen die Aufmerksamkeit und das Interesse der Betrachtenden.

\subsubsection{Professionalität: Authentizität versus Subtilität}

Hinsichtlich der Professionalität fällt die am wenigsten elaborierte Originalvariante deutlich von den beiden anderen Varianten ab, während die mittlere und die hohe Variante ähnlich beurteilt werden (vgl. Grafik 32). Die Variante 〈hoch〉 und die Variante «mittel> werden beide von genau drei Vierteln der Befragten als professionell eingeschätzt. Gleichwohl polarisiert auch hier die orange Variante stärker: Während bei der mittleren Variante der wahrgenommene Professionalitätsgrad in der Grafik konstant abnimmt, wird die elaborierte Variante öfter als nicht professionell bezeichnet. Bei der niedrigen Originalvariante ergibt sich ein dreigeteiltes Bild: Fast gleich viele Personen halten die Variante für professionell, für semiprofessionell und für unprofessionell. Beim Original ist für die Befragten nicht klar, ob «ein Grafiker reingeholt» wurde oder ob jemand die Gestaltung übernommen hat, «der mal einen Kurs besuchte». Für einige Testpersonen wirkt die niedrige Variante gerade aufgrund ihrer nicht ganz professionellen Machart «sympathisch» und «authentisch». Es wird daher sogar vermutet, dass ein guter Grafiker diese Lösung vorgeschlagen haben könnte, um Authentizität herzustellen. 


\section{Einschätzungen zur Elaboration}

Designvarianten Feuerwehr

Mit der FEUERWEHR hoch hinaus!
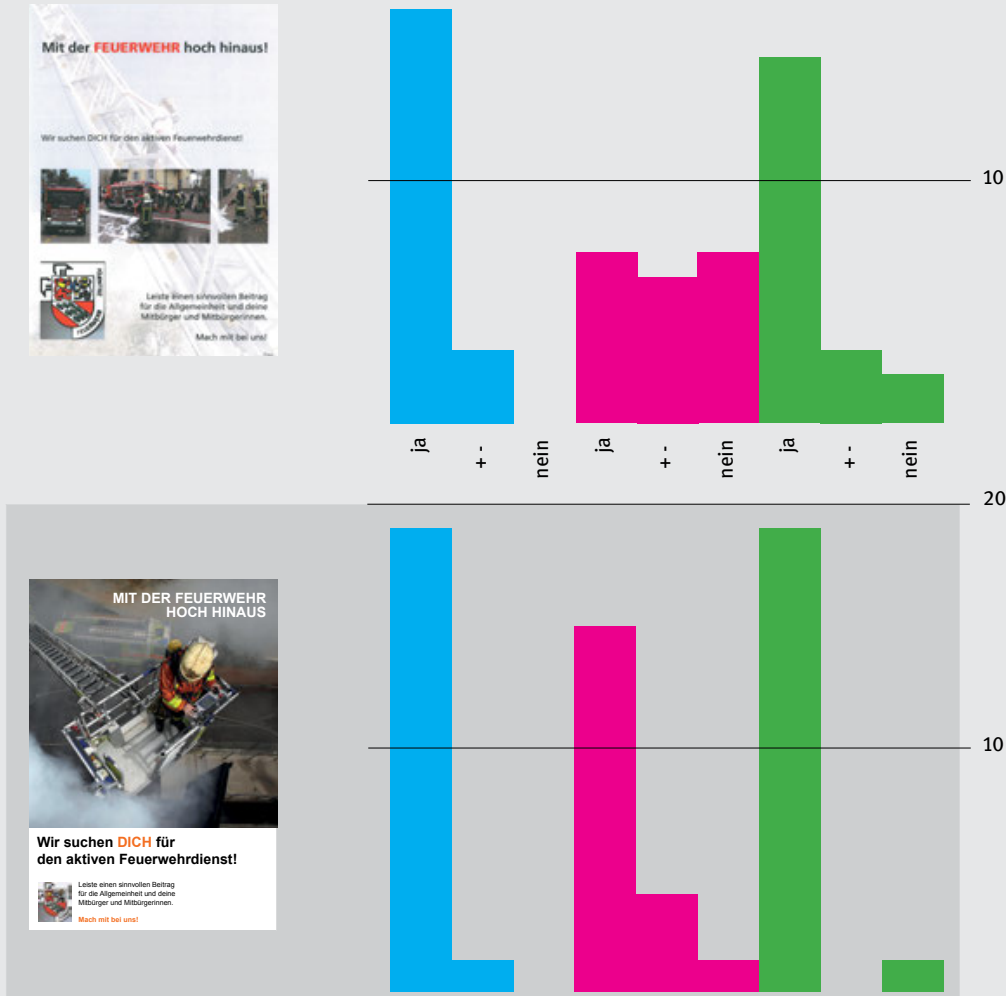

20

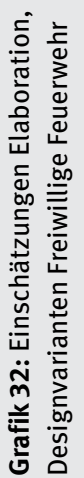

\section{Wir suchen dich}

für den aktiven

\section{Feuerwehrdienst!}

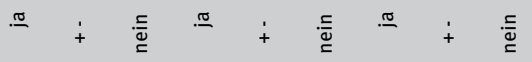

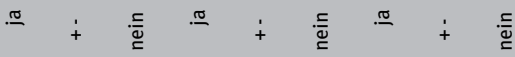


Die Variante 〈hoch〉 wird meist als professionell und «sehr gut gemacht» beurteilt, doch scheinen für die Testpersonen innerhalb dieser Zuordnung noch graduelle Unterschiede zu existieren. So wird die professionelle Erscheinung etwa mit dem Zusatz «gewinnt keinen Designpreis» oder «hat nichts Störendes» relativiert. Merkmale der technischen Ausarbeitung wirken sich dabei auf den wahrgenommenen Professionalitätsgrad aus: Dass die Schrift auf der Vorderseite der elaborierten Variante «nicht mittig, sondern nach oben gesetzt» ist, wird von jemandem als Profimerkmal gedeutet, von einer anderen Person jedoch gerade als Mangel und Indiz für laienhaftes Gebaren. Als Hinweise auf eine professionelle Herkunft der Variante 〈hoch» werden hier außerdem das «Zusammenspiel von Schrift und Farbe», das «subtile Farbenspiel», die «durchgestalteten Streifen» sowie der randabfallende Druck genannt. Einige befinden den Flyer aus «grafischer» Sicht für professionell, aus Sicht einer «adressatengerechten Gestaltung» jedoch für unprofessionell - beziehen also den Angemessenheitsaspekt bereits mit ein in die Beurteilung der Professionalität.

\subsubsection{Angemessenheit: Wirkt gut, funktioniert aber nicht}

Bei der Beurteilung der Angemessenheit findet sich eine überragende Mehrheit für die mittlere Variante: Bis auf eine Person halten alle diese Variante für angemessen (vgl. Grafik 32). Die niedrige Variante erhält hier den zweiten Platz: Sie wirkt zwar nicht unbedingt professionell, wird aber von drei Viertel der Befragten als angemessen beurteilt und eckt nur gerade bei zwei Personen an. Während die elaborierte Variante bezüglich Professionalität noch mit der mittleren gleichauf ist, fällt sie bei der Angemessenheit klar hinter die mittlere Variante zurück. Die Einschätzung der Angemessenheit der Variante 〈hoch〉 führt gar zum kontroversesten Resultat der Versuchsreihe: Etwas mehr als die Hälfte der Testpersonen halten die Variante eindeutig für passend, etwas weniger als die Hälfte dagegen für gänzlich ungeeignet.

Das Hauptargument gegen die Angemessenheit der elaborierten Gestaltungsvariante lässt sich im Votum einer Testperson zusammenfassen: «Wirkt gut, funktioniert aber wohl nicht». Die Gestaltung bewege sich optisch zu weit weg von Kommunikationsmitteln, welche normalerweise im Bereich der Gemeindeund Freiwilligenarbeit zu sehen seien. . Außerdem entspreche sie nicht der Zielgruppe jener, die sich für die Freiwillige Feuerwehr interessieren könnten. Im Unterschied dazu wird vor allem der mittleren, aber auch der niedrigen Variante attestiert, dass sie bei der Zielgruppe ankommen und «ziehen» könnten. Das Original, und in etwas professionellerer Weise die mittlere Variante, stünden für die Institution der Freiwilligen Feuerwehr, wie man sie kenne und wie man es von ihr 
erwarte. Insofern wird den Varianten mit Bild ein klarer Vorteil attestiert, auch wenn ihre Gestaltung vielleicht «weniger schön» sei. Für die Gemeinde als Absenderin reiche auch die niedrige Variante aus. Die etwas krude gestaltete originale Variante widerspiegle sowohl «das Agglomäßige» als auch «das Freiwillige». Erneut spielt hier der Faktor Geld hinein: Da man für die im Flyer propagierte Arbeit nicht bezahlt werde, solle auch die Gestaltung nicht «nach viel Geld» aussehen. Aus einem anderen Blickwinkel dagegen wird eingewandt, dass die typografische Variante ohne Bild «junge Leute», «Lehrlinge und junge Berufsleute» oder ein «urbanes» Publikum besser ansprechen könne als die beiden anderen. Es geht bei all diesen Überlegungen zur Angemessenheit also darum, wie die Zielgruppe, die Absenderinstitution und die Wirkungsintention von den Befragten eingeschätzt werden. Ein Teil der gegensätzlichen Einschätzungen bei der elaborierten Variante lässt sich denn auch auf unterschiedliche Zielsetzungen oder Zielgruppendefinitionen zurückführen: Was und wen soll das Kommunikationsmittel überhaupt erreichen? Wie möchte sich der Absender präsentieren? Wie viel kreativer Spielraum ist angesichts des Kontexts vorhanden? Hierbei spielt auch die Einschätzung der Risikobereitschaft des Absenders eine Rolle: Möchte sich die Freiwillige Feuerwehr Zollikofen mit der Gestaltung auf der sicheren Seite bewegen und auf das Bewährte setzen oder ist sie bereit, sich gestalterisch vorzuwagen bzw. 〈hoch hinaus` zu gehen?

\subsubsection{Knallig oder bewährt? Die Varianten im Vergleich}

Betrachtet man, wie die drei Gestaltungsvarianten des Flugblatts der Freiwilligen Feuerwehr Zollikofen im Vergleich eingestuft werden (vgl. Grafik 33), so zeigt sich, dass hier die Berücksichtigung der Sehgewohnheiten des Zielpublikums und der konventionellen Gestaltung stärker wiegt. Eine überragende Mehrheit hält die klassisch gestaltete, mittlere Variante für die angemessenste. Nur gerade eine Person entscheidet sich hier ausschließlich für die in origineller Weise abweichende elaborierte Variante (immerhin dreimal wird sie zusammen mit einer anderen Variante als angemessenste Variante genannt). Ganze vierzehn Mal wird die Variante 〈hoch〉 hingegen als die am wenigsten angemessene beurteilt. Die niedrige Originalvariante wird zwar von niemandem als die angemessenste eingestuft, da sie von den meisten als «etwas schlechtere» Variation der mittleren Variante betrachtet wird, fällt jedoch nur viermal auf den letzten Platz zurück.

Diese Einschätzungen veranschaulichen noch einmal den deutlichen Unterschied, den Betrachterinnen und Betrachter zwischen der Professionalität und der Angemessenheitgrafischer Kommunikationsmittelmachenkönnen.DenninBezug auf die Professionalität wird die hohe Variante auch in der relativen Einstufung 





immer noch sehr ähnlich wie die mittlere Variante bewertet: $\mathrm{Zu}$ je gut einem Drittel halten die Testpersonen die elaborierte respektive die mittlere Variante für die professionellste und die restlichen Personen (bis auf eine Ausnahme) stufen die hohe und die mittlere Variante gleichwertig als professionellste Varianten ein. Jene Probanden, welche die elaborierte Variante in puncto Professionalität nicht an die Spitze setzen, stufen diese meist gleich als die am wenigsten professionelle Variante ein, so dass die Variante 〈hoch〉 nur gerade zweimal in der Mitte angesiedelt wird. Hier zeigt sich nochmals der kontroverse Charakter der elaborierten Variante. Nicht alle unterscheiden zudem zwischen Professionalität und Angemessenheit. Auch bei diesen Varianten beziehen verschiedene Testpersonen die Angemessenheit bereits bei der Beurteilung der Professionalität mit ein (auf Grafik 33 nicht ersichtlich). Ein Viertel der Probanden stuft die Flyer-Varianten der 〈Freiwilligen Feuerwehr» unter Professionalität und Angemessenheit genau gleich ein. Ein weiteres Viertel setzt zwar hinsichtlich des einen oder anderen Bewertungsaspekts mehrere Varianten auf eine Stufe, wählt jedoch insgesamt dieselbe Reihenfolge. Bei der anderen Hälfte dagegen unterscheiden sich die Einstufungen der Angemessenheit komplett von jenen der Professionalität.

Lassen sich diese Bewertungsunterschiede erneut auf persönliche Faktoren wie Ausbildung oder Wohnort zurückführen? Welche Rolle spielt die Affinität der Befragten zur Feuerwehr? Und zeigen sich in diesem eher «männerlastigen` Bereich vielleicht auch Unterschiede zwischen Männern und Frauen? Tatsächlich ergibt sich auch bei der dritten Serie bei Personen, die außerhalb der Stadt wohnen, etwas öfter eine übereinstimmende Bewertung von Professionalität und Angemessenheit. Allerdings ist der Hauptunterschied vor allem in mehreren stark abweichenden Beurteilungen zu finden, welche bei mehr als der Hälfte der städtisch wohnenden Befragten vorkommt, während nur eine Person aus dem ländlichen Raum eine stark abweichende Anordnung wählt. Diese Differenz schlägt sich jedoch nicht darin nieder, dass auf dem Land und in der Agglomeration anteilsmäßig mehr Personen die mittlere Variante für die angemessenste halten als in der Stadt. Sondern der Unterschied zeigt sich darin, dass in ländlichen Regionen mehr Personen die mittlere Variante für die professionellste halten. Tatsächlich verkehrt sich das Verhältnis bei der Einschätzung der Professionalität der Varianten 〈mittel〉 und 〈hoch〉 im Vergleich zwischen Stadt und Land/Agglomeration sogar: Während im urbanen Kreis die Variante 〈hoch〉 von sieben Personen als die professionellste eingestuft wird, und die mittlere von vier, sind außerhalb der Stadt nur vier Befragte für die professionellste, hingegen sieben für die mittlere Variante. Zudem halten ländlich orientierte Befragte die niedrige Variante etwas häufiger für die angemessenste Variante, auch wenn sie diese nicht als besonders professionell einstufen. Hier entspricht die ländliche Bevölkerung - anders als noch beim Wahlprospekt der BDP - eher der Erwar- 
tung, etwas weniger hohe Anforderungen an die gestalterische Qualität zu haben als städtisch geprägte Personen. Außerhalb der Stadt scheinen zudem konservativere Vorstellungen von Gestaltung vorzuherrschen, die Abweichungen vom Gewohnten weniger tolerieren - oder solche für unprofessionell halten. Aufgrund der Ausbildung der Probanden lassen sich dagegen keine auffälligen Muster und Unterschiede erkennen.

Allerdings unterscheiden sich die Einschätzungen von Männern und Frauen - und zwar vor allem in Bezug auf die abweichende Variante 〈hoch〉. Während die mittlere Variante sowohl in puncto Professionalität als auch in Hinblick Angemessenheit von exakt gleich vielen Männern und Frauen am positivsten eingestuft wird und auch bezüglich der niedrigen Varianten die Einschätzungen vergleichbar sind, erntet die hohe Variante bei den Männern gar keinen Beifall. Keiner der Männer hält die Variante 〈hoch〉 für die angemessenste und sie wird sogar deutlich weniger oft als die professionellste eingestuft als die mittlere Variante. Zwar schneidet der orange Flyer auch bei den Frauen in puncto Angemessenheit deutlich weniger gut ab. Er erhält aber immerhin noch etwa halb so viele Erstplatzierungen wie der mittlere Flyer und läuft dem mittleren Flyer bei der Professionalität den Rang ab. Anders gesagt: Die einzigen vier Stimmen für die höchste Angemessenheitsstufe der Variante 〈hoch〉 kommen von Frauen und die Frauen sorgen dafür, dass die Variante 〈hoch〉 und «mittel〉 insgesamt etwa als gleich professionell abschneiden. Möchte man also weiterhin vor allem Männer rekrutieren, bietet sich die klassisch gestaltete Version als sichere Wahl an. Geht es jedoch darum, auch die Frauen anzusprechen, sollte über ein elaborierteres, originelleres und gestalterisch hochwertigeres Produkt nachgedacht werden, das über die konventionelle Gestaltungsweise hinausgeht.

Die elaborierte Variante erzielt zudem bei den jüngeren Testpersonen bis 30 Jahre eine leicht bessere Akzeptanz. Bei den über 60-Jährigen dagegen votiert überhaupt niemand mehr für den knalligen Flyer als angemessenste Variante, ja sie setzen sogar unter dem Aspekt der Professionalität stets die mittlere vor die hohe Variante. Möchte die Freiwillige Feuerwehr vor allem junge Mitglieder anwerben, wäre somit $\mathrm{zu}$ fragen, ob die konventionelle Elaborationsform des Flyers noch die angebrachteste Lösung ist. Die befragten Testpersonen halten allesamt das Angebot der Freiwilligen Feuerwehr für sehr sinnvoll oder zumindest eher sinnvoll. Aufschlussreicher ist deshalb die Frage, ob sich die Personen vorstellen können, selbst bei der Freiwilligen Feuerwehr mitzumachen - oder gar Mitglieder sind oder früher einmal waren. Unter den Interessierten oder früheren Mitgliedern finden sich keinerlei Voten für die elaborierte Variante - obschon zu dieser Gruppe keineswegs nur Männer zählen. Allerdings sind es eher ältere Personen, die sich ohnehin wenig für diese Variante begeistern. Mehrere Personen, die sich eine Teilnahme 〈vielleicht〉 vorstellen können, erachten dagegen die 
höhere Variante als besonders angemessen. Allenfalls würde sich also für eine Erweiterung des Interessentenfeldes eine Abweichung vom gewohnten Erscheinungsbild empfehlen, um der Feuerwehr ein etwas anderes, etwas frecheres Image zu verleihen - jedoch auf die Gefahr hin, ein bereits von der Sache begeistertes Publikum zu verlieren. 